Discussion Paper No. 882

\title{
DECREASING MARGINAL IMPATIENCE \\ AND CAPITAL ACCUMULATION \\ IN A TWO-COUNTRY WORLD ECONOMY
}

\author{
Ken-Ichi Hirose \\ Shinsuke Ikeda
}

August 2013

The Institute of Social and Economic Research

Osaka University

6-1 Mihogaoka, Ibaraki, Osaka 567-0047, Japan 


\title{
Decreasing Marginal Impatience and Capital Accumulation in a Two-country World Economy
}

\author{
Ken-Ichi Hirose* and Shinsuke Ikeda ${ }^{\dagger}$ \\ Otaru University of Commerce and Osaka University
}

August 2013

\begin{abstract}
This research is the first to examine dynamic general equilibrium in a growing two-country economy under decreasing marginal impatience (DMI). The stability condition is shown to be more restrictive than in the case of an endowment economy and/or under increasing marginal impatience (IMI). By analyzing global-economy adjustment to time preference shocks, international transfers, and productivity shocks, equilibrium dynamics in the presence of DMI differ drastically from what is obtained when the standard IMI model is used. For example, in a country characterized by DMI, a positive productivity shock improves the country's welfare level and lowers its steady-state time preference and, hence, the steady-state interest rate. This leads to an increase in the neighboring country's capital stock.

Keywords: decreasing marginal impatience, two-country economy, capital accumulation.

JEL classification: F41, F32, E00.

*Corresponding author. The Faculty of Commerce, Otaru University of Commerce, 3-5-21 Midori, Otaru, Hokkaido 047-8501, Japan. Telephone: +81(134)27-5365. E-mail:

${ }^{\dagger}$ The Institute of Social and Economic Research, Osaka University, 6-1 Mihogaoka, Ibaraki, Osaka 567-0047, Japan. Telephone: +81(6)6879-8568. Fax: +81(6)6879-8583. E-mail: ikeda@iser.osaka-u.ac.jp
\end{abstract} hirose@res.otaru-uc.ac.jp 


\section{Introduction}

Although many theoretical studies on macroeconomic dynamics have been conducted using endogenous time preferences (e.g., Epstein, 1987a, b; Lucas and Stokey, 1984; Obstfeld, 1990; Ikeda, 2006), it has usually been assumed that the degree of impatience - measured by the pure rate of time preference -is marginally increasing in wealth, thereby ensuring stability. When the degree of impatience is marginally decreasing in wealth, the wealthier are more patient and, ceteris paribus, become even wealthier over time. However, many existing empirical studies often support the validity of decreasing marginal impatience (DMI) (e.g., Lawrance, 1991; Samwick, 1998; Harrison et al., 2002; Ikeda et al., 2006). To develop realistic macroeconomic models, it is necessary to examine dynamic implications of DMI in general equilibrium settings.

Using a two-country capital-accumulation model, the purpose of this paper is to derive theoretical implications of DMI for dynamic stability, open macroeconomic adjustments, and policy effects. This is the first attempt to characterize solutions for a dynamic general equilibrium in a growing twocountry economy under DMI.

A seminal paper by Devereux and Shi (1991) examines a growing twocountry economy within the framework of endogenous time preferences. However, the analysis is limited to the case of increasing marginal impatience (IMI). For example, using the IMI model, they show that a positive productivity shock increases the steady-state interest rate slightly, and hence decreases the neighboring country's capital stock. However, under DMI, the same productivity shock improves the country's welfare level, thereby lowering its steady-state time preference and hence the steady-state interest rate; this increases the neighboring country's capital stock. Similarly, we show that in the presence of DMI, the growing two-country economy exhibits dynamic properties that drastically differ from what is obtained in the usual-but empirically less relevant-IMI setting.

In the literature on DMI, Das (2003) first verifies that DMI is compatible with dynamic stability in a production economy with capital. Hirose and Ikeda (2008) show solution properties under DMI, including optimal satiated consumption. However, they do not discuss the general equilibrium implications of DMI under agent/country heterogeneity. Further, Hirose and Ikeda (2012a, b) solve two-country equilibria under DMI. However, their analysis is restricted to the endowment economy model without capital. 
Supposing that one country has a DMI preference, for the steady-state equilibrium to be saddle-point stable, it is necessary that the other country displays IMI. Although the same property is valid in the case of an endowment economy, the saddle-point stability condition is more restrictive in a capital-accumulation economy than in an endowment economy.

Thus, to investigate the implications of DMI, we consider the case in which one country exhibits DMI while the other country exhibits IMI, with retaining the saddle-point stability of equilibrium dynamics. Then, an upward shift of the subjective discount rate schedule in the IMI country lowers the steady-state interest rate and, hence, increases the steady-state capital stock and output in both counties. This paradoxical result cannot be obtained in the case where both counties exhibit IMI, as in Devereux and Shi (1991).

Considering the saddle-path dynamics after international transfers in a capital-accumulation economy, the interest rate and capital stock sluggishly deviate from their constant steady-state values initially and then return to them. Moreover, although the convergence path of the IMI country's consumption is monotonic, that of the DMI country's consumption is nonmonotonic. Such non-monotonic consumption adjustment after international transfers never emerges if both counties exhibit IMI.

As the effects of improvements in productivity, we obtain the following results. First, the interest rate falls in the long run, although it rises in the short run. Second, the steady-state capital stock and output increase in both countries. Third, the steady-state consumption increases in the DMI country, while it decreases in the IMI country. Fourth, an improvement in the DMI country's productivity typically increases its steady-state net foreign assets, whereas an improvement in the IMI country's productivity typically decreases its steady-state net foreign assets. These results are rather different from those obtained in Devereux and Shi (1991).

The remainder of the paper is organized in the following manner. In Section 2, we construct a growing two-country economy model with endogenous time preference, in which dynamic properties of the equilibrium solution are discussed. In Section 3, we analyze global-economy adjustment to time preference shocks, international transfers, and productivity shocks. In Section 4, we conclude the paper. 


\section{The model}

Suppose that the world economy is composed of two countries 1 and 2, each of which is populated with the same number of infinitely-lived identical households. Without loss of generality, the population is assumed to be one. A single type of goods, which can be either consumed or invested and is tradeable across countries, is produced by competitive firms in both countries using constant-returns-to-scale technologies with capital and labor. Equities representing claims to the capital stock are traded in a perfect international financial market. Letting $a^{i}$ and $k^{i}(i=1,2)$ denote the asset holdings and the capital stock in country $i$, respectively, country $i$ 's net foreign assets $b^{i}$ are expressed as

$$
b^{i}=a^{i}-k^{i}
$$

In each country, one unit of labor is supplied inelastically by the representative household.

\subsection{Households}

The budget constraints for the representative households in country $i$ ( $i=$ $1,2)$ are given by

$$
\dot{a}^{i}=r a^{i}+w^{i}-c^{i},
$$

where $c^{i}$ denote consumption, $w^{i}$ the labor wage, and $r$ the interest rate; and a dot represents the time derivative.

We specify the preferences by assuming variable time preferences as

$$
\max \int_{0}^{\infty} u^{i}\left(c^{i}(t)\right) \exp \left(-\Delta^{i}(t)\right) \mathrm{d} t
$$

where $u^{i}\left(c^{i}\right)(i=1,2)$ represent the instantaneous utility functions; and $\Delta^{i}$ denote cumulative discount rates with instantaneous discount rates $\delta^{i}\left(c^{i}\right)$ : $\Delta^{i}(t)=\int_{0}^{t} \delta^{i}\left(c^{i}(\tau)\right) \mathrm{d} \tau$, or

$$
\dot{\Delta}^{i}(t)=\delta^{i}\left(c^{i}(t)\right), \Delta^{i}(0)=0 .
$$

For intertemporal preferences to be well-defined, we follow the literature (e.g., Epstein, 1987a; Obstfeld 1990; Hirose and Ikeda, 2008) in assuming that the following standard regularity conditions are valid: (C1) $u^{i}<0$ 
$(i=1,2) ;(\mathrm{C} 2) u^{i}$ are strictly increasing and strictly concave in $c^{i} ;(\mathrm{C} 3)-u^{i}$ are $\log$-convex in $c^{i}$; and $(\mathrm{C} 4) \delta^{i}$ are concave in $c^{i}$. It is known, and will be shown later, that the degree of impatience, measured by the rate of time preference, is marginally increasing or decreasing in wealth as the discount rate $\delta^{i}$ is increasing or decreasing in $c^{i}$. Since the regularity conditions, (C1)-(C4), are not related to the signs of the first derivatives of $\delta^{i}$ (hereafter $d \delta^{i} / d c^{i}$ is expressed as $\delta_{c}^{i}$, and so on), the degree of impatience can be either marginally increasing or decreasing under the conditions.

Let $\lambda^{i}$ and $\phi^{i}(i=1,2)$ represent the current-value shadow prices for savings and the discount factor $\exp \left(-\Delta^{i}\right)$, respectively, and the "generating functions" $\xi^{i}$ are defined as

$$
\xi^{i}\left(c^{i}, \phi^{i}\right)=u^{i}\left(c^{i}\right)-\phi^{i} \delta^{i}\left(c^{i}\right) .
$$

Then, the optimal conditions to maximize lifetime utility function (3) are given by

$$
\begin{gathered}
\xi_{c}^{i}\left(c^{i}, \phi^{i}\right)=\lambda^{i}, \\
\dot{\lambda}^{i}=\left(\delta^{i}\left(c^{i}\right)-r\right) \lambda^{i}, \\
\dot{\phi}^{i}=-\xi^{i}\left(c^{i}, \phi^{i}\right), \\
\lim _{t \rightarrow \infty} \exp \left(-\Delta^{i}(t)\right) \lambda^{i}(t) a^{i}(t)=0, \\
\lim _{t \rightarrow \infty} \exp \left(-\Delta^{i}(t)\right) \phi^{i}(t) \Delta^{i}(t)=0,
\end{gathered}
$$

As seen by solving differential equation (8) under transversality condition (10), the optimal $\phi^{i}(t)$ equals the lifetime utility obtained from the optimal consumption stream after time $t$. We assume that the current value marginal utility of $c^{i}$ is positive: $\xi_{c}^{i}\left(c^{i}, \phi^{i}\right)\left(=u_{c}^{i}-\phi^{i} \delta_{c}^{i}\right)>0 .{ }^{1}$

Following Epstein (1987a) and Obstfeld (1990), we define the rate of time preference $\rho^{i}$ as $\rho^{i}=-\mathrm{d} \ln \Gamma^{i}(t) /\left.\mathrm{d} t\right|_{\dot{c}^{i}=0}$, where $\Gamma^{i} \equiv \xi_{c}^{i}\left(c^{i}, \phi^{i}\right) \exp \left(-\Delta^{i}\right)$ represents the present-value marginal utility of $c^{i}$. The time preference rate is computed as

$$
\rho^{i}\left(c^{i}, \phi^{i}\right)=\delta^{i}\left(c^{i}\right)-\frac{\xi^{i}\left(c^{i}, \phi^{i}\right)}{\xi_{c}^{i}\left(c^{i}, \phi^{i}\right)} \delta_{c}^{i}\left(c^{i}\right) .
$$

\footnotetext{
${ }^{1}$ In the following analyses, we assume away a possibility of satiation $\left(\xi_{c}^{i} \leqq 0\right)$ which may occur under decreasing marginal impatience $\left(\delta_{c}^{i}<0\right)$. See Hirose and Ikeda $(2008)$ for the implications of the satiated utility of decreasing marginal impatience consumers.
} 
It is valid that $\rho_{\phi}^{i}=\delta^{i} \delta_{c}^{i} / \xi_{c}^{i}$ around the steady state point in which $\xi^{i}=0$ (see (8)). This implies that the degree of impatience, measured by $\rho^{i}$, is marginally increasing or decreasing in the utility index $\phi^{i}$ as $\delta_{c}^{i}$ is positive or negative. We refer to consumer preferences as increasing marginal impatience (IMI) when $\delta_{c}^{i}$ and hence $\rho_{\phi}^{i}$ are positive, and as decreasing marginal impatience (DMI) when $\delta_{c}^{i}$ and hence $\rho_{\phi}^{i}$ are negative. From (6) and (7), the optimal consumption dynamics can be written in terms of time preference as

$$
\dot{c}^{i}=\sigma^{i}\left(c^{i}, \phi^{i}\right)\left(r-\rho^{i}\left(c^{i}, \phi^{i}\right)\right),
$$

where $\sigma^{i}=-\xi_{c}^{i} / \xi_{c c}^{i}(>0)$.

\section{$2.2 \quad$ Firms}

The per capita production functions for the representative firms in country $i(i=1,2)$ are given by

$$
y^{i}=\alpha^{i} f^{i}\left(k^{i}\right)
$$

satisfying $f_{k}^{i}>0, f_{k k}^{i}<0$, where $y^{i}$ denote output, and $\alpha^{i}$ represent parameters of productivity. We assume that there is no capital depreciation and no adjustment cost of investment. As the results of profit maximization by firms, we obtain

$$
\alpha^{i} f_{k}^{i}\left(k^{i}\right)=r \text { and } \alpha^{i} f^{i}\left(k^{i}\right)-\alpha^{i} f_{k}^{i}\left(k^{i}\right) k^{i}=w^{i} .
$$

In our setup, instantaneous international capital movement may occur, so that we should regard the world total capital stock $K \equiv k^{1}+k^{2}$ as a state variable. Noting that $K=\left(\alpha^{1} f_{k}^{1}\right)^{-1}(r)+\left(\alpha^{2} f_{k}^{2}\right)^{-1}(r)$, where $\left(\alpha^{i} f_{k}^{i}\right)^{-1}$

represents the inverse function of $\alpha^{i} f_{k}^{i}$, the interest rate $r$ can be expressed as a function of $K$ :

$$
r=\gamma(K), \text { where } \gamma_{K}(K)=\frac{\left(\alpha^{1} f_{k k}^{1}\right)\left(\alpha^{2} f_{k k}^{2}\right)}{\alpha^{1} f_{k k}^{1}+\alpha^{2} f_{k k}^{2}}<0 .
$$

\subsection{The market equilibrium}

The market-clearing conditions are given by

$$
c^{1}+c^{2}+\dot{K}=y^{1}+y^{2} \text { and } a^{1}+a^{2}=K .
$$


Then, from (1), (2), (13), (14), and (16), overtime changes in net foreign assets, or the current accounts, $\dot{b}^{i}$ are expressed as

$$
\dot{b}^{i}=r b^{i}+y^{i}-c^{i}-\dot{k}^{i}
$$

From (2), (8), (12), (14), (15), and (16), we can derive the reduced dynamic system as follows:

$$
\begin{gathered}
\dot{c}^{1}=\sigma^{1}\left(c^{1}, \phi^{1}\right)\left(\gamma(K)-\rho^{1}\left(c^{1}, \phi^{1}\right)\right), \\
\dot{c}^{2}=\sigma^{2}\left(c^{2}, \phi^{2}\right)\left(\gamma(K)-\rho^{i}\left(c^{i}, \phi^{i}\right)\right), \\
\dot{\phi}^{1}=\delta^{1}\left(c^{1}\right) \phi^{1}-u^{1}\left(c^{1}\right), \\
\dot{\phi}^{2}=\delta^{2}\left(c^{2}\right) \phi^{2}-u^{2}\left(c^{2}\right), \\
\dot{K}=\alpha^{1} f^{1}\left(\left(\alpha^{1} f_{k}{ }^{1}\right)^{-1}(\gamma(K))\right)+\alpha^{2} f^{2}\left(\left(\alpha^{2} f_{k}^{2}\right)^{-1}(\gamma(K))\right)-c^{1}-c^{2}, \\
\dot{a}^{1}=\alpha^{1} f^{1}\left(\left(\alpha^{1} f_{k}{ }^{1}\right)^{-1}(\gamma(K))\right)+\gamma(K)\left(a^{1}-\left(\alpha^{1} f_{k}\right)^{-1}(\gamma(K))\right)-c^{1} .
\end{gathered}
$$

This dynamic system has two pre-determined state variables, $K$ and $a^{1}$.

\subsection{The steady-state equilibrium}

From (1), (13), (14), (15), (16), (17), and (18) through (23), the steady-state equilibrium is characterized by the following equations:

$$
\begin{gathered}
\delta^{1}\left(c^{1 *}\right)=\delta^{2}\left(c^{2 *}\right)=r^{*}\left(=\gamma\left(K^{*}\right)\right), \\
\alpha^{1} f_{k}^{1}\left(k^{1 *}\right)=\alpha^{2} f_{k}^{2}\left(k^{2 *}\right)=r^{*}\left(=\gamma\left(K^{*}\right)\right), \\
y^{i}=\alpha^{i} f^{i}\left(k^{i}\right)(i=1,2), \\
c^{1 *}+c^{2 *}=y^{1 *}+y^{2 *}, \\
\phi^{i *}=u^{i}\left(c^{i *}\right) / r^{*}(i=1,2), \\
b^{i *}=\left(c^{i *}-y^{i *}\right) / r^{*}(i=1,2), \\
a^{i *}=k^{i *}+b^{i *}(i=1,2),
\end{gathered}
$$

where an asterisk denotes the steady-state value. The values of $c^{1 *}, c^{2 *}, k^{1 *}, k^{2 *}, y^{1 *}, y^{2 *}$ and $r^{*}$ (or $K^{*}$ ) are jointly determined from (24) through (27). Then, $\phi^{i *}$ $(i=1,2)$ are determined from $(28), b^{i *}$ from $(29)$, and $a^{i *}$ from (30). 
By linearizing the dynamic system composed of (18) to (23) around the steady state, we obtain

$$
\left(\begin{array}{c}
\dot{c}^{1} \\
\dot{c}^{2} \\
\dot{\phi}^{1} \\
\dot{\phi}^{2} \\
\dot{K} \\
\dot{a}^{1}
\end{array}\right)=M\left(\begin{array}{c}
c^{1}-c^{1 *} \\
c^{2}-c^{2 *} \\
\phi^{1}-\phi^{1 *} \\
\phi^{1}-\phi^{2 *} \\
K-K^{*} \\
a^{1}-a^{1 *}
\end{array}\right)
$$

with

$$
M=\left(\begin{array}{cccccc}
0 & 0 & -r \delta_{c}^{1} \sigma^{1} / \xi_{c}^{1} & 0 & \gamma_{K} \sigma^{1} & 0 \\
0 & 0 & 0 & -r \delta_{c}^{2} \sigma^{2} / \xi_{c}^{2} & \gamma_{K} \sigma^{2} & 0 \\
-\xi_{c}^{1} & 0 & r & 0 & 0 & 0 \\
0 & -\xi_{c}^{2} & 0 & r & 0 & 0 \\
-1 & -1 & 0 & 0 & r & 0 \\
-1 & 0 & 0 & 0 & \gamma_{K} b^{1} & r
\end{array}\right),
$$

where the coefficient matrix is evaluated at the steady state.

Since this dynamic system has two pre-determined state variables, the steady-state equilibrium is locally saddle-point stable if and only if $M$ has two negative eigenvalues. As proved in Appendix A, we thus obtain the following property. ${ }^{2}$

Property 1: The steady-state equilibrium is locally saddle-point stable if and only if

$$
\left\{\begin{array}{l}
\left(r \delta_{c}^{1}-\gamma_{K}\right)>0,\left(r \delta_{c}^{2}-\gamma_{K}\right)>0, \text { and } \\
\Psi \equiv\left(r \delta_{c}^{1}-\gamma_{K}\right)\left(r \delta_{c}^{2}-\gamma_{K}\right)-\left(\gamma_{K}\right)^{2}>0
\end{array}\right.
$$

Otherwise, the steady-state equilibrium is locally unstable.

Figure 1 displays the region of $\left(\delta_{c}^{1}, \delta_{c}^{2}\right)$ in which the saddle-point stability conditions (32) are satisfied. It makes clear the following property.

Property 2: For the steady-state equilibrium to be saddle-point stable, at least one of the two countries needs to display IMI. If both counties exhibit DMI, the steady-state equilibrium is necessarily unstable.

\footnotetext{
${ }^{2}$ These stability conditions are consistent with the Appendix of Epstein (1987a).
} 
Insert Figure 1.

The same property as Property 2 holds valid in the case of an endowment two-country world economy (e.g., Jafarey and Park, 1998; Hirose and Ikeda, $2012 \mathrm{a}, \mathrm{b})$, in which the saddle-point stability condition is given by

$$
\delta_{c}^{1}+\delta_{c}^{2}>0
$$

Note, however, that, as seen from Figure 1, the saddle-point stability condition in the endowment economy (33) is necessary, but not sufficient, for (32). ${ }^{3}$ This implies the following property.

Property 3: The saddle-point stability condition is more restrictive in our capital-accumulation economy than in the endowment economy.

In addition, the saddle-point stable region with either country having DMI in Figure 1 shrinks as the absolute value of $\gamma_{K}$ becomes smaller. Noting $r=\gamma(K)$, the following property is obtained.

Property 4: As $r$ is less elastic to a change in $K$, the saddle-point stability condition (32) is more restrictive. ${ }^{4}$

To be intuitive, the dynamic system is more easily adjustable in the endowment economy, in which the interest rate can be instantly adjustable upon shocks, than in the capital-accumulation economy, in which the interest rate can change only sluggishly due to overtime changes in the aggregate capital stock. ${ }^{5}$ That is why, as Property 3 shows, the stability condition is more restrictive in our capital-accumation economy. As seen from this discussion, the dynamic adjustablity in our capital-accumulation economy becomes lower as the interest rate is less elastic to a change in the capital stock, as Property 4 states.

\footnotetext{
${ }^{3}$ In Figure 1, $\Psi=0$ is tangent to $\delta_{c}^{1}+\delta_{c}^{2}=0$ at $\left(\delta_{c}^{1}, \delta_{c}^{2}\right)=(0,0)$.

${ }^{4}$ Conversly, (32) approches to (33) as $\left|\gamma_{K}\right| \rightarrow \infty$.

${ }^{5}$ This intuition will be detailed in the analysis of Section 3.2.
} 


\section{The implications of DMI with capital ac- cumulation}

For investigating the implications of DMI in our two-country model with capital accumulation, hereafter, we assume the following saddle-point stability in which one country displays a DMI preference.

Assumption 1: Country 1 exhibits DMI $\left(\delta_{c}^{1}<0\right)$ while country 2 exhibits IMI $\left(\delta_{c}^{2}>0\right)$.

Assumption 2: The saddle-point stability conditions (32) hold valid.

Figure 2 illustrates the determination of the steady-state interest rate $r^{*}$ under these assumptions. By letting $C^{*} \equiv c^{1 *}+c^{2 *}$ and $Y^{*} \equiv y^{1 *}+y^{2 *}$, the "steady-state demand curve" represents the locus of $\left(C^{*}, r^{*}\right)$ satisfying (24), while the "steady-state supply curve" represents the locus of $\left(Y^{*}, r^{*}\right)$ satisfying (25) and (26). Since $C^{*}=Y^{*}$ (i.e., (27)) in equilibrium, $r^{*}$ is determined at the intersection $E$ of these two schedules.

\section{Insert Figure 2.}

The steady-state supply curve is negatively sloping, because a lower interest rate leads to capital accumulation and hence more output is supplied. As derived in Appendix B (see Figure A1), the slope of the steady-state demand curve is also negative under Assumptions 1 and 2. If the steady-state interest rate $r^{*}$ rises, the steady-state consumption demand in DMI country $1 c^{1 *}\left(=\left(\delta_{c}^{1}\right)^{-1}\left(r^{*}\right)\right)$ decreases while the steady-state consumption demand in DMI country $2 c^{2 *}\left(=\left(\delta_{c}^{2}\right)^{-1}\left(r^{*}\right)\right)$ increases. Under Assumption 2, we have $\left|\delta_{c}^{1}\right|<\left|\delta_{c}^{2}\right|$ and hence $\left|\left(\delta_{c}^{1}\right)^{-1}\right|>\left|\left(\delta_{c}^{2}\right)^{-1}\right|$, implying that $c^{1 *}$ is more elastic than $c^{2 *}$ in response to a change in $r^{*}$. Accordingly, a rise in $r^{*}$ decreases the steady-state world total consumption demand $C^{*}$.

Besides, the slope of the steady-state supply curve is steeper than that of the steady-state demand curve. The slopes of the steady-state demand and supply curves are given by $\frac{d r^{*}}{d C^{*}}=\frac{\delta_{c}^{1} \delta_{c}^{2}}{\delta_{c}^{1}+\delta_{c}^{2}}$ and $\frac{d r^{*}}{d Y^{*}}=\frac{\gamma_{K}}{r}$, respectively. Under Assumptions 1 and $2, \Psi>0$ in (32) implies that $(0>) \frac{\delta_{c}^{1} \delta_{c}^{2}}{\delta_{c}^{1}+\delta_{c}^{2}}>\frac{\gamma_{K}}{r}$. 


\subsection{Shifts in time preference}

At first, we consider the effects of upward shifts of subjective discount rate schedules. See Figure 3. When a upward shift in the subjective discount rate schedule takes place in DMI country 1, its result is quite natural. As shown in Appendix B (see Figure A2 (i)), a upward shift in the $\delta^{1}$-schedule shifts the steady-state demand curve upward. In Figure 3, this upward shift in the steady-state demand curve brings the intersection with the steady-state supply curve from $E$ to $E^{\prime}$, implying that the steady-state interest rate $r^{*}$ rises and the capital stock are decumulated. This result is the same as in the case where both two countries have the IMI preferences (e.g., Devereux and Shi, 1991).

\section{Insert Figure 3.}

When a upward shift in the subjective discount rate schedule occurs in IMI country 2, it leads to a paradoxical result. As shown in Appendix B (see Figure A2 (ii)), an upward shift in the $\delta^{2}$-schedule shifts the steady-state demand curve downward. In Figure 3, this downward shift in the steady-state demand curve brings the intersection with the steady-state supply curve from $E$ to $E^{\prime \prime}$. Although the subjective discount rate schedule shifts upward, the steady-state interest rate $r^{*}$ lowers and capital accumulation is stimulated.

Proposition 1: Suppose that country 1 has DMI whereas country 2 has IMI (Assumption 1), and that the saddle-point stability conditions are met (Assumption 2). Then, an upward shift of the subjective discount rate schedule in IMI country 2 paradoxically lowers the steady-state interest rate, and hence increases the steady-state capital stock and output in both counties.

\subsection{International transfers}

Given the initial values of the state variables $K(0)$ and $a^{1}(0)$, the linearized

solution of the saddle-path dynamics is analytically calculated in Appendix C.

Let us analyze the effects of international transfers. Suppose that the world economy is initially at the steady-state equilibrium and some wealth 
is transferred from one country to the other at time 0. By using a numerical example given in Table 1, Figures 4 (a) and 4 (b) illustrate the saddle-path dynamics in response to international transfers, where (a) represents a case of a transfer from IMI country 2 to DMI country 1, and (b) represents a case of a transfer from IMI country 1 to DMI country 2.

\section{Insert Figures 4 (a) \& 4 (b).}

Insert Table 1.

The recipient country's lifetime utility naturally improves while the donor country's lifetime utility becomes worse. ${ }^{6}$ In our model, however, international transfers have no long-run effects, because the steady-state equilibrium does not depend on the initial asset stocks (see (24) to (30)).

In our model with two state variables, there exists a possibility of nonmonotonic saddle-path dynamics. In fact, the saddle-path dynamics after international transfers show the following non-monotonic characteristics, as seen in Figures 4 (a) and 4 (b).

Proposition 2: In our capital-accumulation economy under Assumptions 1 and 2, the saddle-path dynamics after international transfers have the following characteristics.

(i) The interest rate and the capital stock initially and sluggishly deviate from their constant steady-state values and then return to them again.

(ii) A transfer from IMI country to DMI country causes the interest rate deviate downwards, while a transfer from DMI country to IMI country causes the interest rate deviate upwards.

(iii) The time path of DMI country's consumption is non-monotonic, whereas that of IMI country's is monotonic.

For understanding these non-monotonic dynamics in our capital-accumulation economy, it would be helpful to compare them with monotonic dynamics in

\footnotetext{
${ }^{6}$ In these examples, we assume that initial net foreign assets are zero. With non-zero initial net foreign assets, the transfer might harm the recipient country and benefit the donor country by changing the interest rate. This dynamic version of the transfer paradix was pointed out by Epstein (1987a).
} 
a endowment economy. Figures 5 (a) and 5 (b) depicts the effects of international transfers in the case of the endowment economy. ${ }^{7}$

Insert Figures 5 (a) \& 5 (b).

In Figure 5 (a), a transfer from IMI country 2 to DMI country 1 initially makes both countries patient. In Figure 5 (b), in contrast, a transfer from DMI country 1 to IMI country 2 initially makes both countries impatient. The saddle-point stability condition in the endowment economy (i.e., (33)), which is met under Assumption 2, requires that the donor country (i.e., country 2 in (a); country 1 in (b)) become more patient than the recipient country (i.e., country 1 in (a); country 2 in (b)). In the endowment economy, the interest rate $r$ is determined as a weighted sum of the two countries' rates of time preference $\rho^{1}$ and $\rho^{2} .8$ The donor country, whose rate of time preference is lower than $r$, accumulates wealth, whereas the recipient country, whose rate of time preference is higher than $r$, decumulates wealth. As a result, the world economy monotonically converges to the steady state.

In the capital-accumulation economy, the impact effects of the international transfers on $\rho^{1}$ and $\rho^{2}$ are similar as those in the endowment economy, but the interest rate cannot change instantaneously. Accordingly, $r(0)>$ $\rho^{1}(0)>\rho^{2}(0)$ is valid in Figure $4(\mathrm{a})$, and $r(0)<\rho^{1}(0)<\rho^{2}(0)$ in Figure 4 (b). For stability, $r$ must be adjusted finally into the region between $\rho^{1}$ and $\rho^{2}$, that is, the inequalities between $r$ and $\rho^{1}$ need to be reversed by overtime changes in $K$, as illustrated in Figures 4 (a) and 4 (b). If the interest rate is so inelastic that the inequalities between $r$ and $\rho^{1}$ keep eternally unchanged, the economy cannot converge to the steady state. ${ }^{9}$

From (12), DMI country's consumption $c^{1}$ also shows non-monotonic adjustment, because the inequality relationships between $r$ and $\rho^{1}$ is reversed midway on the saddle path. On the other hand, IMI country's consumption $c^{2}$ monotonically converges to the steady-state level, since the inequality relationship between $r$ and $\rho^{2}$ never changes. If both countries exhibit IMI

\footnotetext{
${ }^{7}$ The endowment is given by the steady-state output level in Table 1 (i.e., $y^{1}=y^{2}=20$ ).

${ }^{8}$ In the endowment economy, $r(t)=\frac{\sigma^{1}}{\sigma^{1}+\sigma^{2}} \rho^{1}(t)+\frac{\sigma^{1}}{\sigma^{1}+\sigma^{2}} \rho^{2}(t)$ (see e.g., eq.(12) in Hirose and Ikeda, 2012a).

${ }^{9}$ This argument details the intuitive reason for Properties 3 and 4 mentioned in the end of Section 2.4.
} 
(as in Devereux and Shi, 1991), non-monotonic consumption adjustment is not brought about by such international transfers. ${ }^{10}$ We thus find that nonmonotonic consumption adjustment after international transfers is specific only to a DMI country in the capital-accumulation economy.

\subsection{Improvements in productivity}

Next, we investigate the effects of improvements in productivity $\alpha^{i}(i=1,2)$. The mathematical results of the steady-state effects, derived from (24) to (30), are given by Table 2 .

Insert Table 2.

\subsubsection{An improvement in DMI country's productivity}

Column (I) of Table 3 displays the qualitative results of the steady-state effects of an improvement in DMI country 1's productivity $\alpha^{1}$.

Insert Table 3.

An improvement in $\alpha^{1}$ lowers the steady-state interest rate $r^{*}$. As illustrated in Figure 6, it shifts the steady-state supply curve rightward and brings the intersection with the steady-state demand curve from $E$ to $\tilde{E}$, implying that $r^{*}$ falls. Therefore, not only in country 1 experiencing an improvement in productivity but also in neighboring country 2 , the steady-state capital stock and output increase. In DMI country 1, the steady-state consumption and lifetime utility increase. Because the increase in the steady-state consumption is larger than that in the steady-state output, country 1's steady-state

\footnotetext{
${ }^{10}$ In Devereux and Shi (1991), international transfers do not affect the interest rate and the capital stock even in the short run. This result is, however, due to a special assumption for their lifetime utility function. When both country have IMI, generally speaking, the effects of international transfers on the interest rate and the capital stock are ambiguous.
} 
net foreign assets typically increase. ${ }^{11}$ In neighboring IMI country 2, the steady-state consumption and lifetime utility decrease.

\section{Insert Figure 6.}

Concerning the impact effects of an improvement in productivity, we can find analytically the following two facts. First, the impact effects on the interest rate is positive, though its steady-state effect is negative. Noting that $K=k^{1}+k^{2}$ cannot change instantaneously, from (14) (or (15)), the interest rate must rise immediately after a production shock, accompanied by instantaneous capital movement to the country experiencing an improvement in productivity from the neighboring country.

Second, the impact effect on the welfare of the country with a productivity improvement is definitely positive and the impact effect on the welfare of the neighboring country is approximately zero, when $b^{1}(0)=b^{2}(0)=0$. From Table 2 and Appendix C, we can obtain that

$$
\begin{gathered}
\left.\frac{d \phi^{i}(0)}{d \alpha^{i}}\right|_{b^{i}(0)=0}=\frac{\xi_{c}^{i} f^{i}}{r}(>0)(i=1,2), \\
\left.\frac{d \phi^{j}(0)}{d \alpha^{i}}\right|_{b^{i}(0)=0}=0(j \neq i) .
\end{gathered}
$$

\subsubsection{An improvement in IMI country's productivity}

Column (II) of Table 3 summarizes the qualitative results of the steady-state effects of an improvement in IMI country 2's productivity $\alpha^{2}$.

An improvement in $\alpha^{2}$ lowers the steady-state interest rate $r^{*}$, similarly as in the previous case of an improvement in $\alpha^{1}$ (see again Figure 6), so that the steady-state capital stock and output increase in both countries. However, the steady-state effects on consumption and lifetime utility contrast to those in the previous case. In the country with a productivity improvement, since it is IMI country 2, the steady-state consumption and lifetime utility decrease, and therefore the steady-state net foreign assets also typically decrease. In

\footnotetext{
${ }^{11}$ If country 1 has huge net foreign debt initially, it may be able to increase steady-state net foreign debt, because the interest payment decreases due to a fall in $r^{*}$.
} 
the neighboring DMI country 1, the steady-state consumption and lifetime utility increase.

In this case as well as in the the previous case of an improvement in $\alpha^{1}$, the impact effects on the interest rate is positive in spite of the negative steady-state effect on it; the impact effect on the welfare of the country with a productivity improvement is positive; and the spill-over effect on the welfare of the neighboring country $\left(\phi^{1}(0)\right)$ is negligible, when $b^{1}(0)=b^{2}(0)=0$ (see (34) and (35)).

The effects of improvements in productivity can be summarized as follows.

Proposition 3: In our setting under Assumptions 1 and 2, suppose that productivity in one country improves. Then, we can obtain the following results:

(i) The interest rate falls in the long run, although it rises in the short run after the production shock.

(ii) In both countries, the capital stock is accumulated and the steady-state output increases.

(iii) Whichever country experiences an improvement in productivity, the steady-state consumption increases in the DMI country whereas it decreases in the IMI country.

Moreover, supposing that the initial net foreign assets are zero, we can also say the followings:

(iv) An improvement in productivity of one country improves the country's welfare and has no spill-over effect on the neighboring country's welfare.

(v) An improvement in the DMI country's productivity increases its steadystate net foreign assets, while an improvement in the IMI country's productivity decreases its steady-state net foreign assets.

\subsubsection{Comparison with the case of two IMI countries}

Finally, let us compare our results summarized as Proposition 3 with the one in Devereux and Shi (1991) (hereafter D-S) where both two countries have IMI preference. In Table 3, Column (III) summarizes the results in the D-S case. Four points are especially deserving of notice.

First, the effects on the steady-state interest rate are opposite to those in the D-S setting. An improvement in productivity raises $r^{*}$ in the D-S setting whereas it reduces $r^{*}$ in our setting, irrespective of in which country the productivity improvement occurs (Proposition 3 (i)). 
Second, improvements in productivity commonly increase the world total output. In the D-S setting, however, the output increases only in the country experiencing an improvement in productivity, while the output in the neighboring country decreases due to capital decumulation. In our setting, by contrast, the steady-state output increases in both countries (Proposition 3 (ii)).

Third, increases in the steady-state world total consumption are brought by improvements in productivity. In the D-S setting, the steady-state consumption increases in both countries, implying that benefits of improvements in productivity are shared by both countries in the long run. In our setting, whichever country experiences a productivity improvement, the steady-state consumption increases only in the DMI country. It decreases in the IMI country (Proposition 3 (iii)).

Fourth, the effect on the steady-state net foreign assets in our setting depends on whether an improvement in productivity happens in the DMI country or in the IMI country (Proposition $3(\mathrm{v})$ ). This result is quite different from the one in the D-S setting, where the steady-state net foreign assets of the country experiencing an improvement in productivity always decrease.

Consequently, the prediction in D-S that countries with higher (lower) productivity should be long-run debtors (creditors) is not necessarily valid in our setting. In the D-S setting, benefits of higher productivity are shared between both countries in the long run, so that countries with higher productivity can diminish net foreign assets.

In our setting, the effect on the interest rate affects significantly the international distribution of steady-state consumption, that is, under the lower steady-state interest rate associated with higher productivity, steady-state consumption tends to be biased toward the DMI country. Owing to this effect, contrary to the D-S case, a country with higher productivity is more likely to be a long-run creditor if it has DMI.

\section{Conclusion}

This paper has investigated the implications of DMI in a two-country world economy with capital accumulation. Supposing that one country has a DMI preference, for the steady-state equilibrium to be saddle-point stable, it is necessary that the other country displays IMI. Although the same property is valid in the case of an endowment economy, saddle-point stability condition is 
more restrictive in our capital-accumulation economy than in the endowment economy.

For investigating the implications of DMI, we thus consider the case in which one country exhibits DMI while the other country exhibits IMI, with retaining the saddle-point stability of the equilibrium dynamics. Then, an upward shift of the subjective discount rate schedule in IMI country lowers the steady-state interest rate, and hence increases the steady-state capital stock and output in both counties. This paradoxical result cannot be obtained in the case where both counties display IMI as in Devereux and Shi (1991).

Considering the saddle-path dynamics after international transfers in our capital-accumulation economy, the interest rate and the capital stock initially and sluggishly deviate from their constant steady-state values and then return to them again. Besides, although the convergence path of IMI country's consumption is monotonic, that of DMI country's consumption is nonmonotonic. Such non-monotonic consumption adjustment after international transfers never emerges if both counties have IMI preference.

As the effects of improvements in productivity, we obtain the following results. First, the interest rate falls in the long run, although it rises in the short run. Second, the steady-state capital stock and output increase in both countries. Third, the steady-state consumption increases in the DMI country while it decreases in the IMI country. Fourth, an improvement in the DMI country's productivity typically increases its steady-state net foreign assets, whereas an improvement in the IMI country's productivity typically decreases its steady-state net foreign assets. These results also quite differ from those in the case of Devereux and Shi (1991). 


\section{Appendix A: The proof of Proposition 1}

The characteristic equation of $M$ is given by

$$
\operatorname{det}\left(M-x I_{6}\right)=(x-r)^{2} \Omega(x)=0,
$$

where

$$
\begin{aligned}
\Omega(x) & =\left\{x^{2}(x-r)^{2}-\omega x(x-r)+\psi\right\} \\
& \left.=x^{4}-2 r x^{3}+\left(r^{2}-\omega\right) x^{2}+r \omega x+\psi\right), \\
\omega & =\left(r \delta_{c}^{1}-\gamma_{K}\right) \sigma^{1}+\left(r \delta_{c}^{2}-\gamma_{K}\right) \sigma^{2}, \\
\psi & =\left(r^{2} \delta_{c}^{1} \delta_{c}^{2}-r \delta_{c}^{1} \gamma_{K}-r \delta_{c}^{2} \gamma_{K}\right) \sigma^{1} \sigma^{2} .
\end{aligned}
$$

By letting $\tilde{x}=x-\frac{1}{2} r, \Omega(x)=0$ is rewritten as

$$
\tilde{x}^{4}-\frac{1}{2}\left(r^{2}+2 \omega\right) \tilde{x}^{2}+\frac{1}{16} r^{4}+\frac{1}{4} r^{2} \omega+\psi=0 .
$$

Therefore,

$$
\begin{aligned}
& \tilde{x}^{2}=\frac{1}{4}\left\{r^{2}+2 \omega \pm \sqrt{(2 \omega)^{2}-16 \psi}\right\} \\
& \tilde{x}= \pm \frac{1}{2} \sqrt{r^{2}+2 \omega \pm \sqrt{(2 \omega)^{2}-16 \psi}}
\end{aligned}
$$

and hence,

$$
x=\frac{1}{2}\left\{r \pm \sqrt{r^{2}+2 \omega \pm \sqrt{(2 \omega)^{2}-16 \psi}}\right\} .
$$

Note that $(2 \omega)^{2}-16 \psi=4\left\{\left(r \delta_{c}^{1}-\gamma_{K}\right) \sigma^{1}-\left(r \delta_{c}^{2}-\gamma_{K}\right) \sigma^{2}\right\}^{2}+4\left(\gamma_{K}\right)^{2} \sigma^{1} \sigma^{2}>0$.

Let us denote

$$
\begin{aligned}
& x_{1}=\frac{1}{2}\left\{r-\sqrt{r^{2}+2 \omega+\sqrt{(2 \omega)^{2}-16 \psi}}\right\}, \\
& x_{2}=\frac{1}{2}\left\{r-\sqrt{r^{2}+2 \omega-\sqrt{(2 \omega)^{2}-16 \psi}}\right\}, \\
& x_{3}=\frac{1}{2}\left\{r+\sqrt{r^{2}+2 \omega-\sqrt{(2 \omega)^{2}-16 \psi}}\right\}, \\
& x_{4}=\frac{1}{2}\left\{r+\sqrt{r^{2}+2 \omega+\sqrt{(2 \omega)^{2}-16 \psi}}\right\} .
\end{aligned}
$$

The signs of $x_{1}, x_{2}, x_{3}$, and $x_{4}$ depend on the signs of $\omega$ and $\psi$ as Table A1. 
Insert Table A1.

Therefore, the characteristic equation of $M$ has two negative roots, implying that the steady-state equilibrium is locally saddle-point stable, if and only if $\omega>0$ and $\psi>0$, or equivalently,

$$
\left\{\begin{array}{l}
\left(r \delta_{c}^{1}-\gamma_{K}\right)>0,\left(r \delta_{c}^{2}-\gamma_{K}\right)>0, \text { and } \\
\Psi \equiv\left(r \delta_{c}^{1}-\gamma_{K}\right)\left(r \delta_{c}^{2}-\gamma_{K}\right)-\left(\gamma_{K}\right)^{2}>0
\end{array}\right.
$$

Otherwise, the characteristic equation of $M$ has one or no negative root, so that the steady-state equilibrium is unstable.

\section{Appendix B: The derivation of the steady-state demand curve}

Figure A1 derives the negative slope of the steady-state demand curve under Assumptions 1 and 2. When the steady-state world total consumption demand is given by $C_{M}^{*}$, for example, $r_{M}^{*}$ which satisfies $\delta^{1}\left(c^{1 *}\right)=\delta^{2}\left(c^{2 *}\right)=$ $r_{M}^{*}$ and $c^{1 *}+c^{2 *}=C_{M}^{*}$ is given by the height of the intersection $X_{M}$ of $\delta^{1}\left(c^{1 *}\right)$-schedule and $\delta^{2}\left(C_{M}^{*}-c^{1 *}\right)$-schedule. The point $\left(C_{M}^{*}, r_{M}^{*}\right)$ thus needs to be on the steady-state demand curve. Similarly as $\left(C_{M}^{*}, r_{M}^{*}\right)$, we can obtain $\left(C_{L}^{*}, r_{L}^{*}\right),\left(C_{H}^{*}, r_{H}^{*}\right)$ and so on. The steady-state demand curve is the locus of these points. Because country 1 has DMI $\left(\delta_{c}^{1}<0\right)$ and country 2 has IMI $\left(\delta_{c}^{2}>0\right)$, the $\delta^{1}\left(c^{1 *}\right)$-schedule and the $\delta^{2}\left(C^{*}-c^{1 *}\right)$-schedule are both negative sloping. From Corollary $1,\left|\delta_{c}^{1}\right|<\left|\delta_{c}^{2}\right|$, that is, the slope of the $\delta^{2}\left(C^{*}-c^{1 *}\right)$-schedule is steeper than that of the $\delta^{1}\left(c^{1 *}\right)$-schedule. Then, we find that $r_{L}^{*}>r_{M}^{*}>r_{H}^{*}$ for $C_{L}^{*}<C_{M}^{*}<C_{H}^{*}$, implying that the steady-state demand curve is negatively sloping.

\section{Insert Figure A1.}

By using this derivation of the steady-state demand curve, Figure A2 (i) shows that it shifts upward when an upward shift in the $\delta^{1}$-schedule occurs, whereas Figure A2 (ii) shows that it shifts downward when an upward shift in the $\delta^{2}$-schedule takes place. 
Insert Figures A2 (i) \& (ii).

\section{Appendix C: The linearized solution of the saddle- path dynamics}

Eigenvectors of $M$ corresponding $x_{1}$ and $x_{2}\left(x_{1}<x_{2}<0\right)$ are

$$
\left(\begin{array}{c}
\left(r-x_{1}\right) v_{1}^{1} \\
\left(r-x_{1}\right) v_{1}^{2} \\
\xi_{c}^{1} v_{1}^{1} \\
\xi_{c}^{2} v_{1}^{2} \\
1 \\
\tilde{v}_{1}^{1}
\end{array}\right) \text { and }\left(\begin{array}{c}
\left(r-x_{2}\right) v_{2}^{1} \\
\left(r-x_{2}\right) v_{2}^{2} \\
\xi_{c}^{1} v_{2}^{1} \\
\xi_{c}^{2} v_{2}^{2} \\
1 \\
\tilde{v}_{2}^{1}
\end{array}\right)
$$

respectively, where

$$
\begin{aligned}
v_{1}^{1} & =\frac{\gamma_{K} \sigma^{1}}{x_{1}\left(r-x_{1}\right)+r \delta_{c}^{1} \sigma^{1}}, \quad v_{1}^{2}=\frac{\gamma_{K} \sigma^{2}}{x_{1}\left(r-x_{1}\right)+r \delta_{c}^{2} \sigma^{2}}\left(=1-v_{1}^{1}\right), \\
v_{2}^{1} & =\frac{\gamma_{K} \sigma^{1}}{x_{2}\left(r-x_{2}\right)+r \delta_{c}^{1} \sigma^{1}}, \quad v_{2}^{2}=\frac{\gamma_{K} \sigma^{2}}{x_{2}\left(r-x_{2}\right)+r \delta_{c}^{2} \sigma^{2}}\left(=1-v_{2}^{1}\right), \\
\tilde{v}_{1}^{1} & =v_{1}^{1}-\frac{\gamma_{K} b^{1}}{r-x_{1}}, \quad \tilde{v}_{2}^{1}=v_{2}^{1}-\frac{\gamma_{K} b^{1}}{r-x_{2}},
\end{aligned}
$$

and $x_{j}\left(r-x_{j}\right)+r \delta_{c}^{2} \sigma^{2} \neq 0(j=1,2)$ are assumed.

The solution of (31) is thus

$$
\begin{gathered}
c^{1}(t)=c^{1 *}+Z_{1}\left(r-x_{1}\right) v_{1}^{1} \exp \left(x_{1} t\right)+Z_{2}\left(r-x_{2}\right) v_{2}^{1} \exp \left(x_{2} t\right), \\
c^{2}(t)=c^{2 *}+Z_{1}\left(r-x_{1}\right) v_{1}^{2} \exp \left(x_{1} t\right)+Z_{2}\left(r-x_{2}\right) v_{2}^{2} \exp \left(x_{2} t\right), \\
\phi^{1}(t)=\phi^{1 *}+Z_{1} \xi_{c}^{1} v_{1}^{1} \exp \left(x_{1} t\right)+Z_{2} \xi_{c}^{1} v_{2}^{1} \exp \left(x_{2} t\right), \\
\phi^{2}(t)=\phi^{2 *}+Z_{1} \xi_{c}^{2} v_{1}^{2} \exp \left(x_{1} t\right)+Z_{2} \xi_{c}^{2} v_{2}^{2} \exp \left(x_{2} t\right), \\
K(t)=K^{*}+Z_{1} \exp \left(x_{1} t\right)+Z_{2} \exp \left(x_{2} t\right), \\
a^{1}(t)=a^{1 *}+Z_{1} \tilde{v}_{1}^{1} \exp \left(x_{1} t\right)+Z_{2} \tilde{v}_{2}^{1} \exp \left(x_{2} t\right),
\end{gathered}
$$

where

$$
Z_{1}=\frac{1}{\tilde{v}_{2}^{1}-\tilde{v}_{1}^{1}}\left\{-\tilde{v}_{2}^{1}\left(K^{*}-K(0)\right)+\left(a^{1 *}-a^{1}(0)\right)\right\}
$$




$$
Z_{2}=\frac{1}{\tilde{v}_{2}^{1}-\tilde{v}_{1}^{1}}\left\{\tilde{v}_{1}^{1}\left(K^{*}-K(0)\right)-\left(a^{1 *}-a^{1}(0)\right)\right\} .
$$

Noting that $r-r^{*}=\alpha^{1} f_{k k}^{1}\left(k^{1}-k^{1 *}\right)=\alpha^{2} f_{k k}^{2}\left(k^{2}(t)-k^{2 *}\right)=\gamma_{K}\left(K-K^{*}\right)$ by linearizing (14) and (15), we obtain that

$$
\begin{gathered}
r(t)=r^{*}+\gamma_{K}\left\{Z_{1} \exp \left(x_{1} t\right)+Z_{2} \exp \left(x_{2} t\right)\right\}, \\
k^{1}(t)=k^{1 *}+\frac{\gamma_{K}}{\alpha^{1} f_{k k}^{1}}\left\{Z_{1} \exp \left(x_{1} t\right)+Z_{2} \exp \left(x_{2} t\right)\right\}, \\
k^{2}(t)=k^{2 *}+\frac{\gamma_{K}}{\alpha^{2} f_{k k}^{2}}\left\{Z_{1} \exp \left(x_{1} t\right)+Z_{2} \exp \left(x_{2} t\right)\right\},
\end{gathered}
$$

and hence, from (1),

$$
b^{1}(t)=b^{1 *}+Z_{1}\left(\tilde{v}_{1}^{1}-\frac{\gamma_{K}}{\alpha^{1} f_{k k}^{1}}\right) \exp \left(x_{1} t\right)+Z_{2}\left(\tilde{v}_{2}^{1}-\frac{\gamma_{K}}{\alpha^{1} f_{k k}^{1}}\right) \exp \left(x_{2} t\right) .
$$




\section{References}

[1] Das, M, 2003. Optimal growth with decreasing marginal impatience. Journal of Economic Dynamics \& Control 27, 1881-1898.

[2] Devereux, M., Shi, S., 1991. Capital accumulation and the current account in a two-country model. Journal of International Economics 30, $1-25$.

[3] Epstein, L.G., 1987a. A simple dynamic general equilibrium model. Journal of Economic Theory 41, 68-95.

[4] Epstein, L.G., 1987b. The global stability of efficient intertemporal allocations. Econometrica 55, 329-355.

[5] Epstein, L.G., Hynes, J.A., 1983. The rate of time preference and dynamic economic analysis. Journal of Political Economy 91, 611-625.

[6] Harrison, G.W., Lau, M.I., Williams, M.B., 2002. Estimating individual discount rates in Denmark: A field experiment. American Economic Review 92, 1606-1617.

[7] Hirose, K., Ikeda, S., 2008. On decreasing marginal impatience. Japanese Economic Review 59, 259-274.

[8] Hirose, K., Ikeda, S., 2012a. Decreasing marginal impatience in a twocountry economy. Journal of Economics 105, 247-262.

[9] Hirose, K., Ikeda, S., 2012b. Decreasing and Increasing Marginal Impatience and the Terms of Trade in an Interdependent World Economy. Journal of Economic Dynamics \& Control 36, 1551-1565.

[10] Ikeda, S., 2001. Weakly non-separable preferences and the HarbergerLaursen-Metzler effect. Canadian Journal of Economics 34, 290-307.

[11] Ikeda, S., 2006. Luxury and wealth. International Economic Review 47, 495-526.

[12] Ikeda, S., Ohtake, F., Tsutsui, Y., 2006. Time discounting, hyperbolic discounting, and intertemporal choices: Evidences from experiments and questionnaires. mimeo. 
[13] Jafarey, S., Park, H., 1998. The dynamics of optimal wealth distributions with recursive utility. Economic Letters 61, 149-158.

[14] Lawrance, E.C., 1991. Poverty and the rate of time preference, Evidence from panel data. Journal of Political Economy 99, 54-77.

[15] Lucas, R., Stokey, N., 1984. Optimal growth with many consumers. Journal of Economic Theory 32, 139-171.

[16] Obstfeld, M., 1982. Aggregate spending and the terms of trade: Is there a Laursen-Metzler effect?. Quarterly Journal of Economics 97, 251-270.

[17] Obstfeld, M., 1990. Intertemporal dependence, impatience, and dynamics. Journal of Monetary Economics 26, 45-76.

[18] Samwick, A.A., 1998. Discount rate heterogeneity and social security reform. Journal of Development Economics 57, 117-146.

[19] Svensson, L.E.O., Razin, A., 1983. The terms of trade and the current account: The Harberger-Laursen-Metzler effect. Journal of Political Economy 91, 97-125.

[20] Uzawa, H., 1968. Time Preference, the consumption function and optimum asset holdings, in: Wolfe J.N. (Ed.), Value Capital and Growth: Papers in Honour of Sir John Hicks. Aldine, Chicago, pp.485-504. 
Table 1: A numerical example under Assumptions 1 and 2

\begin{tabular}{|c|c|c|}
\hline function & country 1 & country 2 \\
\hline $\begin{array}{c}\text { subjective } \\
\text { discount } \\
\text { rate }\end{array}$ & $\left.\begin{array}{c}\text { DMI }: \delta_{c}^{1}=-0.0005 \\
\delta^{1}\left(c^{1}\right) \fallingdotseq-0.0005 c^{1}+0.06 \\
\text { around } c^{1}=20\end{array}\right)$ & $\left.\begin{array}{c}\text { IMI }: \delta_{c}^{2}=0.001 \\
\delta^{2}\left(c^{2}\right) \fallingdotseq 0.001 c^{2}+0.03 \\
\text { around } c^{2}=20\end{array}\right)$ \\
\hline $\begin{array}{c}\text { utility } \\
\text { function }\end{array}$ & $u^{i}\left(c^{i}\right)=-\left(c^{i}-50\right)^{2}, c^{i} \in[0,50)$ \\
\hline $\begin{array}{c}\text { production } \\
\text { function }\end{array}$ & $\alpha^{i} f^{i}\left(k^{i}\right)=2 \sqrt{10}\left(k^{i}\right)^{0.25}$ \\
\end{tabular}

\begin{tabular}{|c|c|c|}
\hline steady-state value & country 1 & country 2 \\
\hline interest rate & \multicolumn{2}{|c|}{$r^{*}=0.05$} \\
\hline capital stock & $k^{1 *}=100$ & $k^{2 *}=100$ \\
\hline output & $y^{1 *}=20$ & $y^{2 *}=20$ \\
\hline consumption & $c^{1 *}=20$ & $c^{2 *}=20$ \\
\hline lifetime utility & $\phi^{1 *}=-18000$ & $\phi^{2 *}=-18000$ \\
\hline net foreign assets & $b^{1 *}=0$ & $b^{2 *}=0$ \\
\hline
\end{tabular}

Note: $\gamma_{K}=-1.875 \times 10^{-4}, \Psi=3.4375 \times 10^{-9}$ 
Table 2: The mathematical results of the steady-state effects of improvements in productivity $\left(\begin{array}{l}\text { country } i: \text { the country experiencing an improvement in productivity } \\ \text { country } j: \text { the neighboring country }\end{array}\right)$

\begin{tabular}{|l|}
\hline$\frac{d r^{*}}{d \alpha^{i}}=-\frac{r \delta_{c}^{1} \delta_{c}^{2} \gamma_{K}}{\Psi}\left(f^{i}-\frac{r f_{k}^{i}}{\alpha^{i} f_{k k}^{i}}\right)$ \\
\hline$\frac{d K^{*}}{d \alpha^{i}}=-\frac{r \delta_{c}^{1} \delta_{c}^{2}}{\Psi}\left(f^{i}-\frac{r f_{k}^{i}}{\alpha^{i} f_{k k}^{i}}\right)-\frac{f_{k}^{i}}{\alpha^{i} f_{k k}^{i}}$ \\
\hline$\frac{d k^{i}}{d \alpha^{i}}=\frac{1}{\alpha^{i} f_{k k}^{i}}\left\{-\frac{r \delta_{c}^{1} \delta_{c}^{2} \gamma_{K}}{\Psi}\left(f^{i}-\frac{r f_{k}^{i}}{\alpha^{i} f_{k k}^{i}}\right)-f_{k}^{i}\right\}$ \\
\hline$\frac{d k^{j *}}{d \alpha^{i}}=\frac{1}{\alpha^{j} f_{k k}^{j}}\left\{-\frac{r \delta_{c}^{1} \delta_{c}^{2} \gamma_{K}}{\Psi}\left(f^{i}-\frac{r f_{k}^{i}}{\alpha^{i} f_{k k}^{i}}\right)\right\}$ \\
\hline$\frac{d y^{i *}}{d \alpha^{i}}=\left\{\frac{r}{\alpha^{i} f_{k k}^{i}}\left(-\frac{r \delta_{c}^{1} \delta_{c}^{2} \gamma_{K}}{\Psi}\right)+1\right\}\left(f^{i}-\frac{r f_{k}^{i}}{\alpha^{i} f_{k k}^{i}}\right)$ \\
\hline$\frac{d y^{j *}}{d \alpha^{i}}=\frac{r}{\alpha^{j} f_{k k}^{j}}\left\{-\frac{r \delta_{c}^{1} \delta_{c}^{2} \gamma_{K}}{\Psi}\left(f^{i}-\frac{r f_{k}^{i}}{\alpha^{i} f_{k k}^{i}}\right)\right\}$ \\
\hline$\frac{d c^{i *}}{d \alpha^{i}}=-\frac{r \delta_{c}^{j} \gamma_{K}}{\Psi}\left(f^{i}-\frac{r f_{k}^{i}}{\alpha^{i} f_{k k}^{i}}\right)$ \\
\hline$\frac{d c^{j *}}{d \alpha^{i}}=-\frac{r \delta_{c}^{i} \gamma_{K}}{\Psi}\left(f^{i}-\frac{r f_{k}^{i}}{\alpha^{i} f_{k k}^{i}}\right)$ \\
\hline$\frac{d \phi^{i *}}{d \alpha^{i}}=-\frac{\delta_{c}^{j} \gamma_{K} \xi_{c}^{i}}{\Psi}\left(f^{i}-\frac{r f_{k}^{i}}{\alpha^{i} f_{k k}^{i}}\right)$ \\
\hline$\frac{d \phi^{j *}}{d \alpha^{i}}=-\frac{\delta_{c}^{i} \gamma_{K} \xi_{c}^{j}}{\Psi}\left(f^{i}-\frac{r f_{k}^{i}}{\alpha^{i} f_{k k}^{i}}\right)$ \\
\hline$\frac{d b^{i *}}{d \alpha^{i}}=\left\{\left(\frac{1}{\delta_{c}^{i}}-\frac{r}{\alpha^{i} f_{k k}^{i}}\right)\left(-\frac{\delta_{c}^{1} \delta_{c}^{2} \gamma_{K}}{\Psi}\right)-\frac{1}{r}\right\}\left(f^{i}-\frac{r f_{k}^{i}}{\alpha^{i} f_{k k}^{i}}\right)-\frac{\delta_{c}^{1} \delta_{c}^{2} \gamma_{K}}{\Psi}\left(f^{i}-\frac{r f_{k}^{i}}{\alpha^{i} f_{k k}^{i}}\right) b^{i}(0)$ \\
\hline$\frac{d b^{j *}}{d \alpha^{i}}=\left(\frac{1}{\delta_{c}^{j}}-\frac{r}{\alpha^{j} f_{k k}^{j}}\right)\left\{-\frac{\delta_{c}^{1} \delta_{c}^{2} \gamma_{K}}{\Psi}\left(f^{i}-\frac{r f_{k}^{i}}{\alpha^{i} f_{k k}^{i}}\right)\right\}-\frac{\delta_{c}^{1} \delta_{c}^{2} \gamma_{K}}{\Psi}\left(f^{i}-\frac{r f_{k}^{i}}{\alpha^{i} f_{k k}^{i}}\right) b^{j}(0)$ \\
\hline$\frac{d a^{i *}}{d \alpha^{i}}=\left[\left(\frac{r}{\gamma_{K}}-\frac{1}{\delta_{c}^{j}}\right)\left\{-\frac{\delta_{c}^{1} \delta_{c}^{2} \gamma_{K}}{\Psi}\left(f^{i}-\frac{r f_{k}^{i}}{\alpha^{i} f_{k k}^{i}}\right)\right\}-\frac{f_{k}^{i}}{\alpha^{i} f_{k k}^{i}}\right]-\frac{\delta_{c}^{1} \delta_{c}^{2} \gamma_{K}}{\Psi}\left(f^{i}-\frac{r f_{k}^{i}}{\alpha^{i} f_{k k}^{i}}\right) b^{i}(0)$ \\
\hline$\frac{d j^{j *}}{d \alpha^{i}}=\left\{-\frac{\delta_{c}^{i} \gamma_{K}}{\Psi}\left(f^{i}-\frac{r f_{k}^{i}}{\alpha^{i} f_{k k}^{i}}\right)\right\}-\frac{\delta_{c}^{1} \delta_{c}^{2} \gamma_{K}}{\Psi}\left(f^{i}-\frac{r f_{k}^{i}}{\alpha^{i} f_{k k}^{i}}\right) b^{j}(0)$ \\
\hline
\end{tabular}


Table 3: The qualitative results of the steady-state effects of improvements in productivity ( $\left.\begin{array}{l}\text { country } i: \text { the country experiencing an improvement in productivity } \\ \text { country } j: \text { the neighboring country }\end{array}\right)$

\begin{tabular}{|c|c|c|c|c|}
\hline \multirow{2}{*}{\multicolumn{2}{|c|}{$\begin{array}{c}\text { the effects of } \\
\text { an improvement } \\
\text { in } \alpha^{i}\end{array}$}} & $(\mathrm{I})$ & (II) & (III) \\
\hline & & $\begin{array}{c}\text { country } i: \mathrm{DMI} \\
\text { country } j: \mathrm{IMI} \\
(i=1, j=2)\end{array}$ & $\begin{array}{c}\text { country } i: \text { IMI } \\
\text { country } j: \text { DMI } \\
(i=2, j=1)\end{array}$ & $\begin{array}{c}\text { country } i: \text { IMI } \\
\text { country } j: \text { IMI } \\
(\mathrm{D}-\mathrm{S}, 1991)\end{array}$ \\
\hline \multirow{7}{*}{ country $i$} & $r^{*}$ & - & - & + \\
\hline & $K^{*}$ & + & + & $?$ \\
\hline & $k^{i *}$ & + & + & $?$ \\
\hline & $y^{i *}$ & + & + & + \\
\hline & $c^{i *}, \phi^{i *}$ & + & - & + \\
\hline & $b^{i *}$ & + & - & - \\
\hline & $a^{i *}$ & + & - & $?$ \\
\hline \multirow{5}{*}{ country $j$} & $k^{j *}$ & + & + & - \\
\hline & $y^{j *}$ & + & + & - \\
\hline & $c^{j *}, \phi^{j *}$ & - & + & + \\
\hline & $b^{j *}$ & - & + & + \\
\hline & $a^{j *}$ & - & + & + \\
\hline
\end{tabular}

Note: The effects on $b^{i *}, b^{j *}, a^{i *}$, and $a^{j *}$ are obtained when $b^{1}(0)=b^{2}(0)=0$. 
Table A1: The signs of $x_{i}(i=1,2,3,4)$

\begin{tabular}{|c|c|c|c|}
\hline & $\psi>0$ & $\psi=0$ & $\psi<0$ \\
\hline \multirow{2}{*}{$\omega>0$} & $x_{1}<0, x_{2}<0$, & $x_{1}<0, x_{2}=0$, & $x_{1}<0, x_{2}>0$, \\
& $x_{3}>0, x_{4}>0$ & $x_{3}>0, x_{4}>0$ & $x_{3}>0, x_{4}>0$ \\
\hline \multirow{2}{*}{$\omega=0$} & $\left(\begin{array}{c}\text { inconsistent with } \\
(2 \omega)^{2}-16 \psi>0\end{array}\right)$ & $\left(\begin{array}{c}\text { inconsistent with } \\
(2 \omega)^{2}-16 \psi>0\end{array}\right)$ & $x_{1}<0, x_{2}>0$, \\
& $x_{3}>0, x_{4}>0$ \\
\hline \multirow{2}{*}{$\omega<0$} & $x_{1}>0, x_{2}>0$, & $x_{1}=0, x_{2}>0$, & $x_{1}<0, x_{2}>0$, \\
& $x_{3}>0, x_{4}>0$ & $x_{3}>0, x_{4}>0$ & $x_{3}>0, x_{4}>0$ \\
\hline
\end{tabular}

Note: $x_{i}>0(i=1,2,3,4)$ include the cases of imaginary roots with positive real parts. 


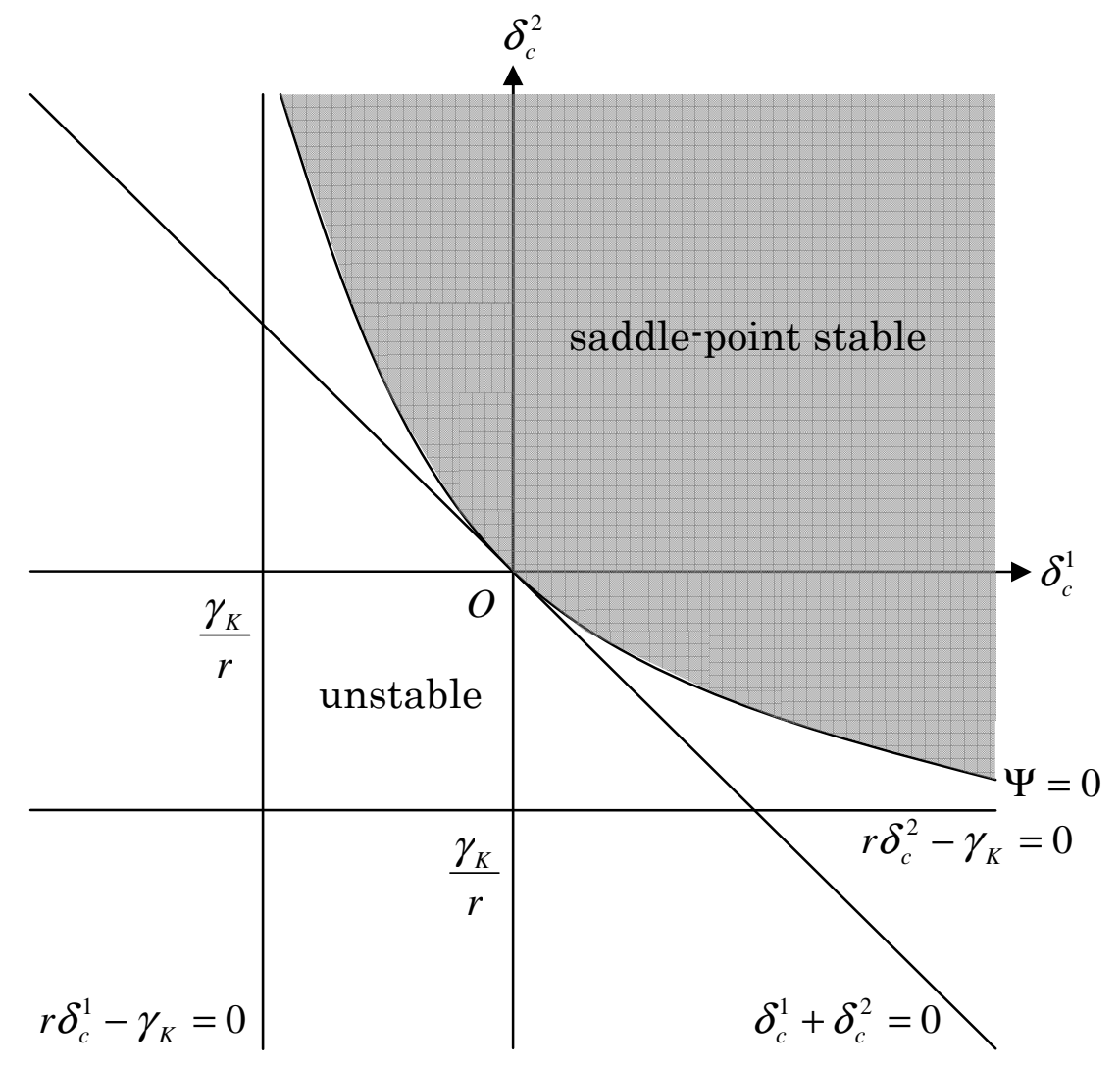

Figure 1. The saddle-point stability conditions 


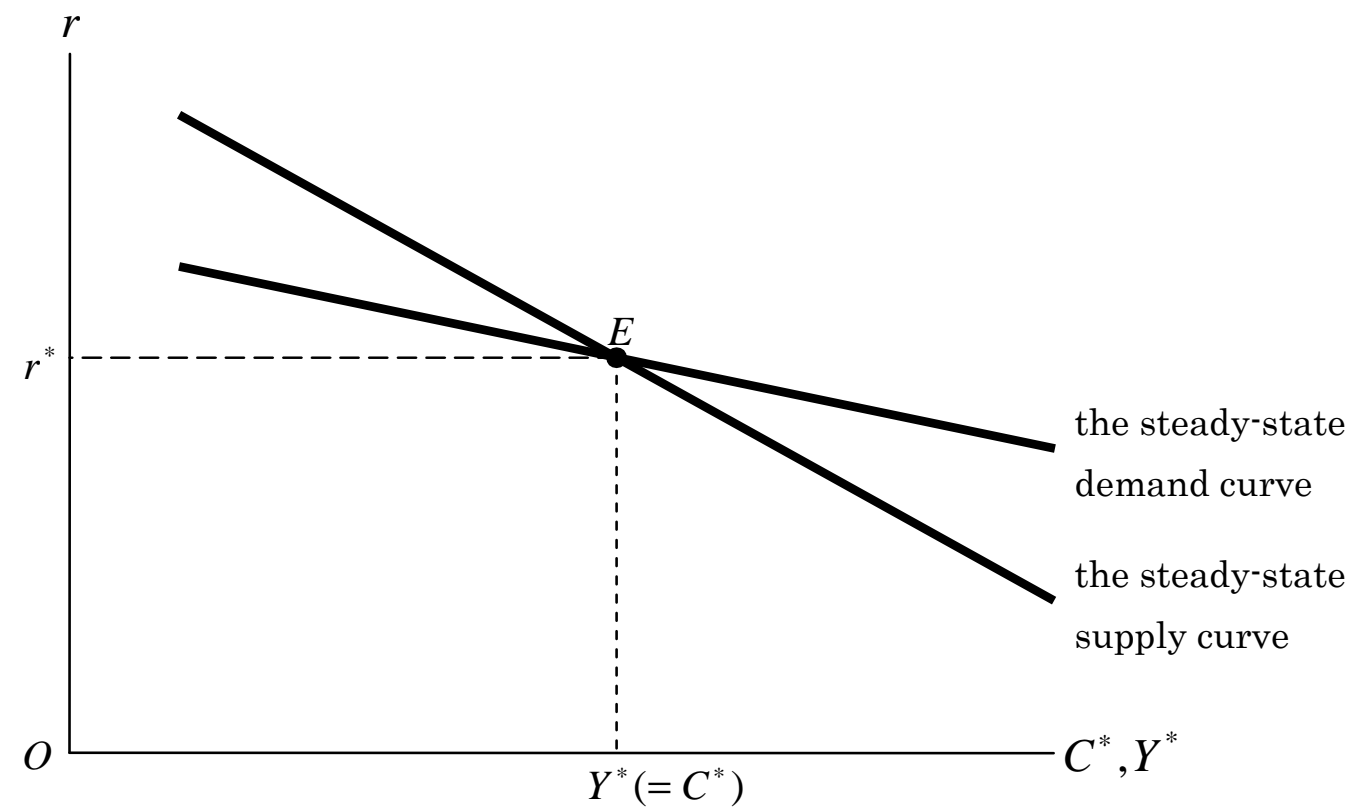

Figure 2. The steady-state supply curve and the steady-state demand curve 


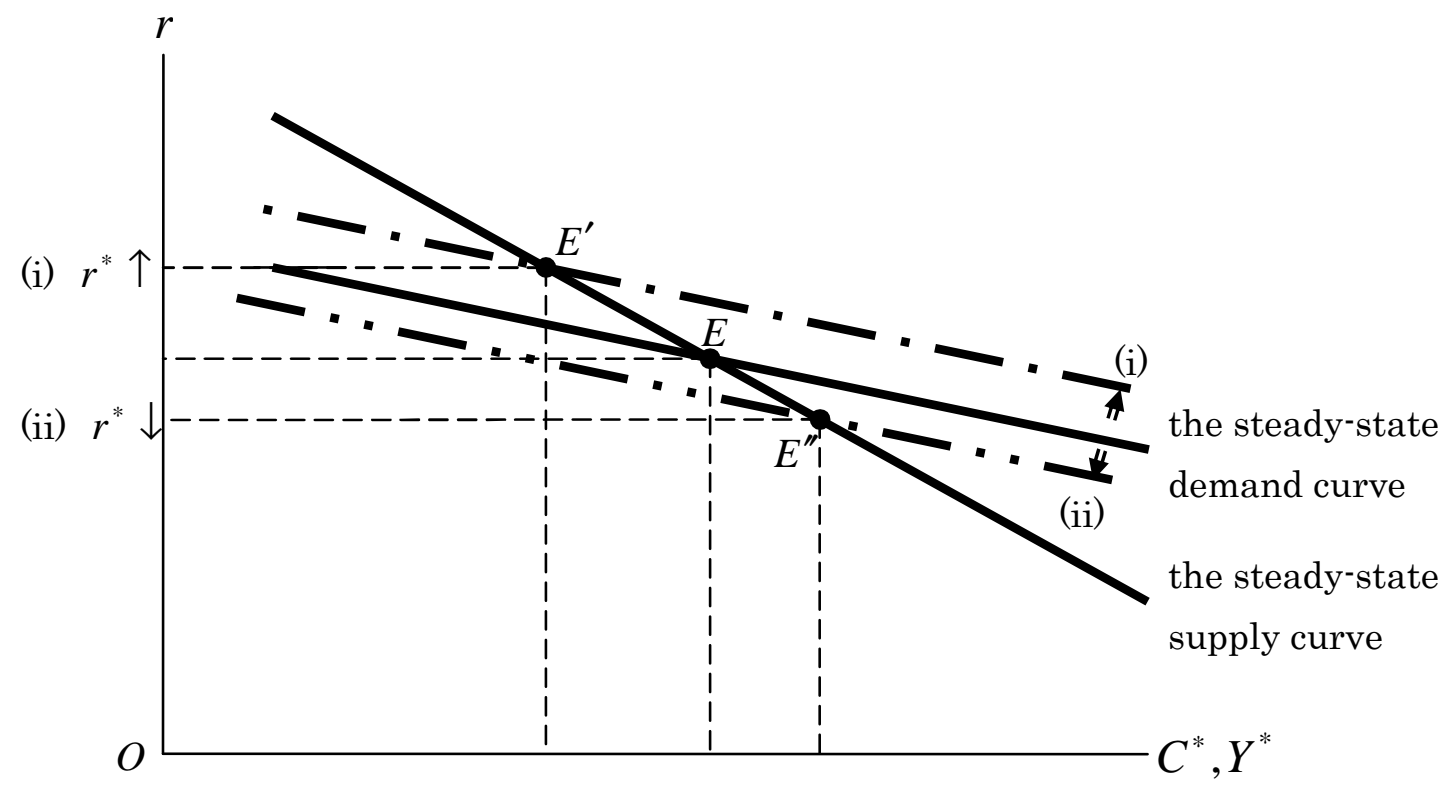

Figure 3. The effects of shifts in subjective discount rate schedules

(i) upward shift in $\delta^{1}$-schedule

(ii) upward shift in $\delta^{2}$-schedule 

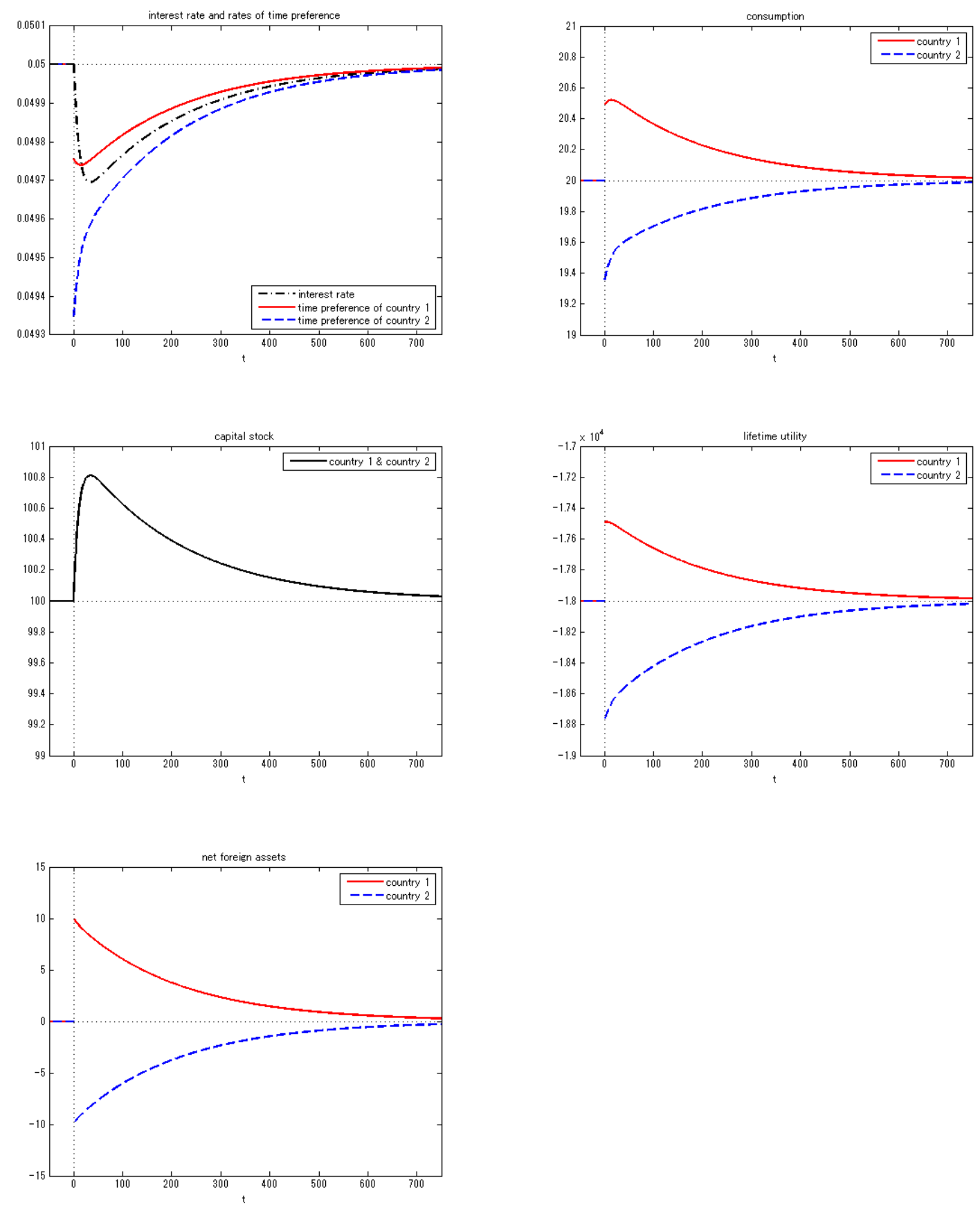

Figure 4. (a) The saddle-path dynamics in the capital-accumulation economy: the case of transfer from IMI country 2 to DMI country 1 

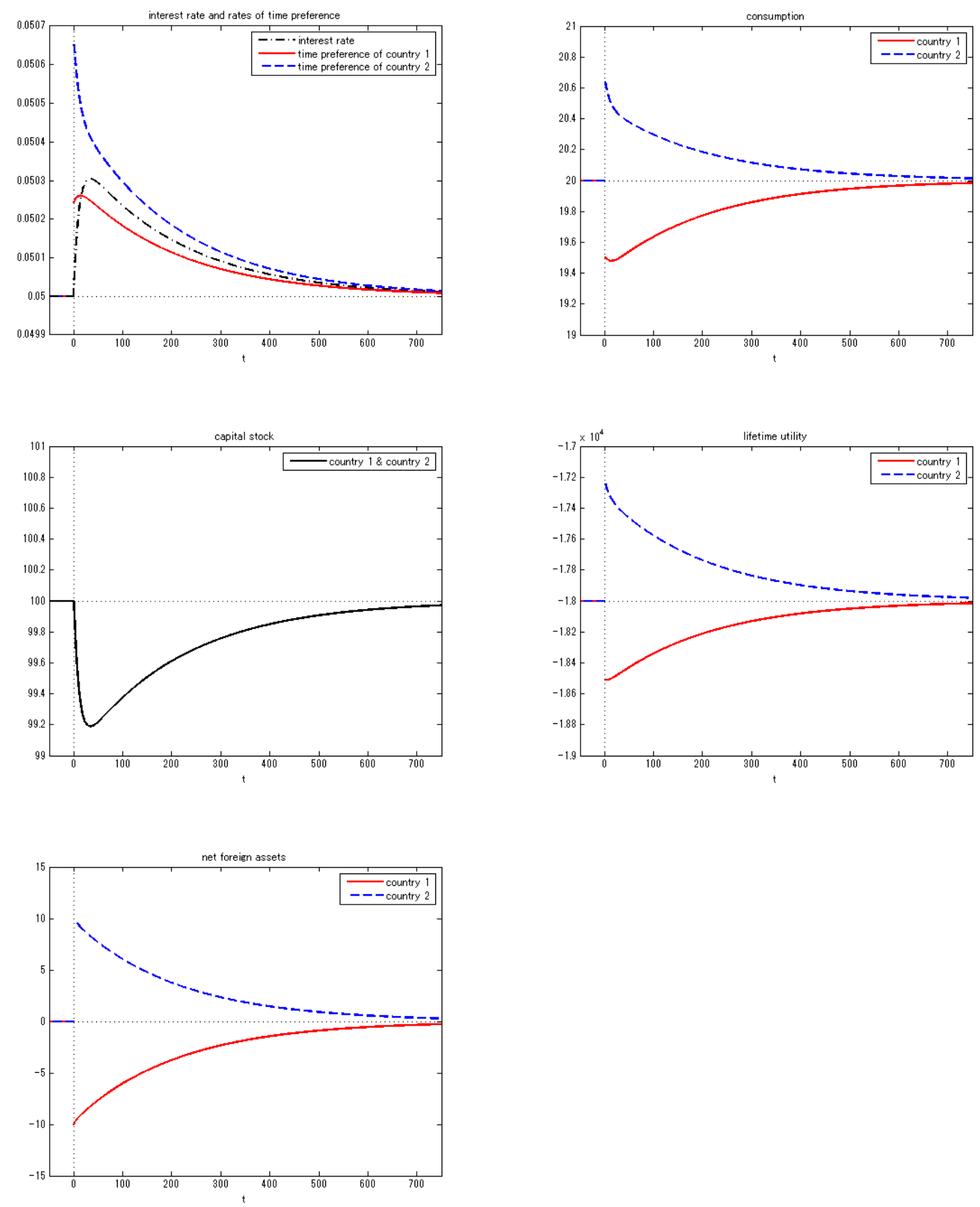

Figure 4. (b) The saddle-path dynamics in the capital-accumulation economy: the case of transfer from DMI country 1 to IMI country 2 

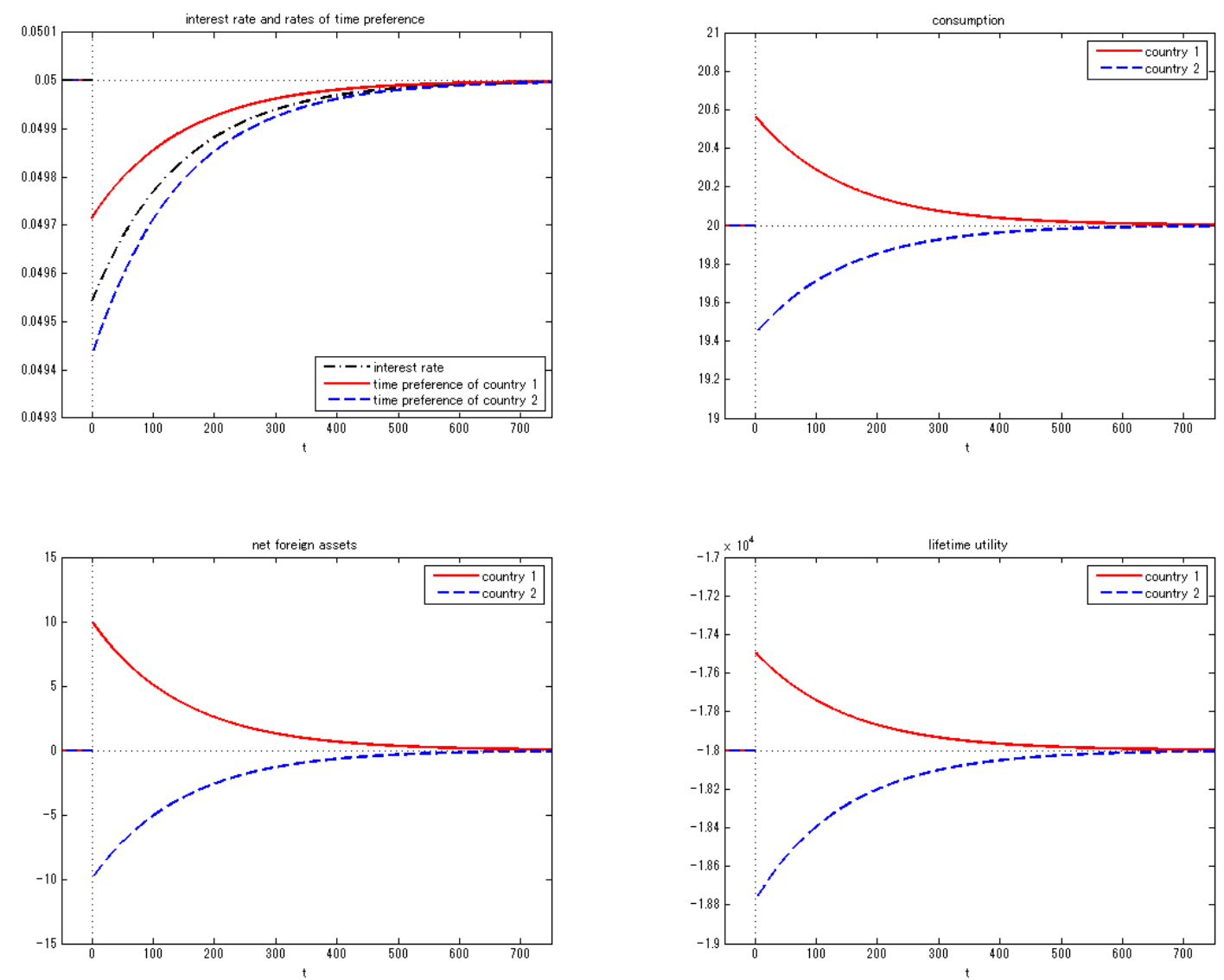

Figure 5. (a) The saddle-path dynamics in the endowment economy: the case of transfer from IMI country 2 to DMI country 1 

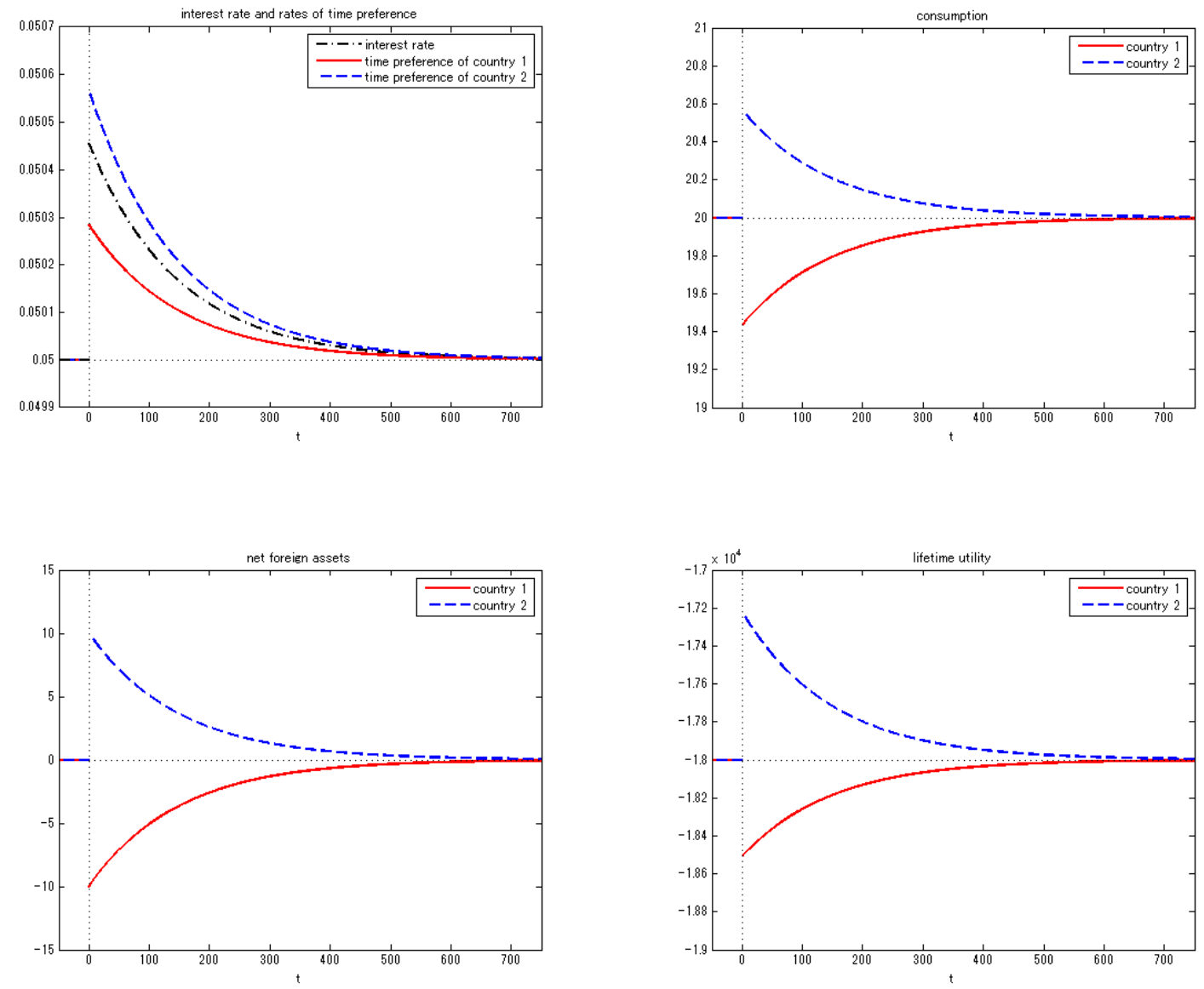

Figure 5. (b) The saddle-path dynamics in the endowment economy: the case of transfer from DMI country 1 to IMI country 2 


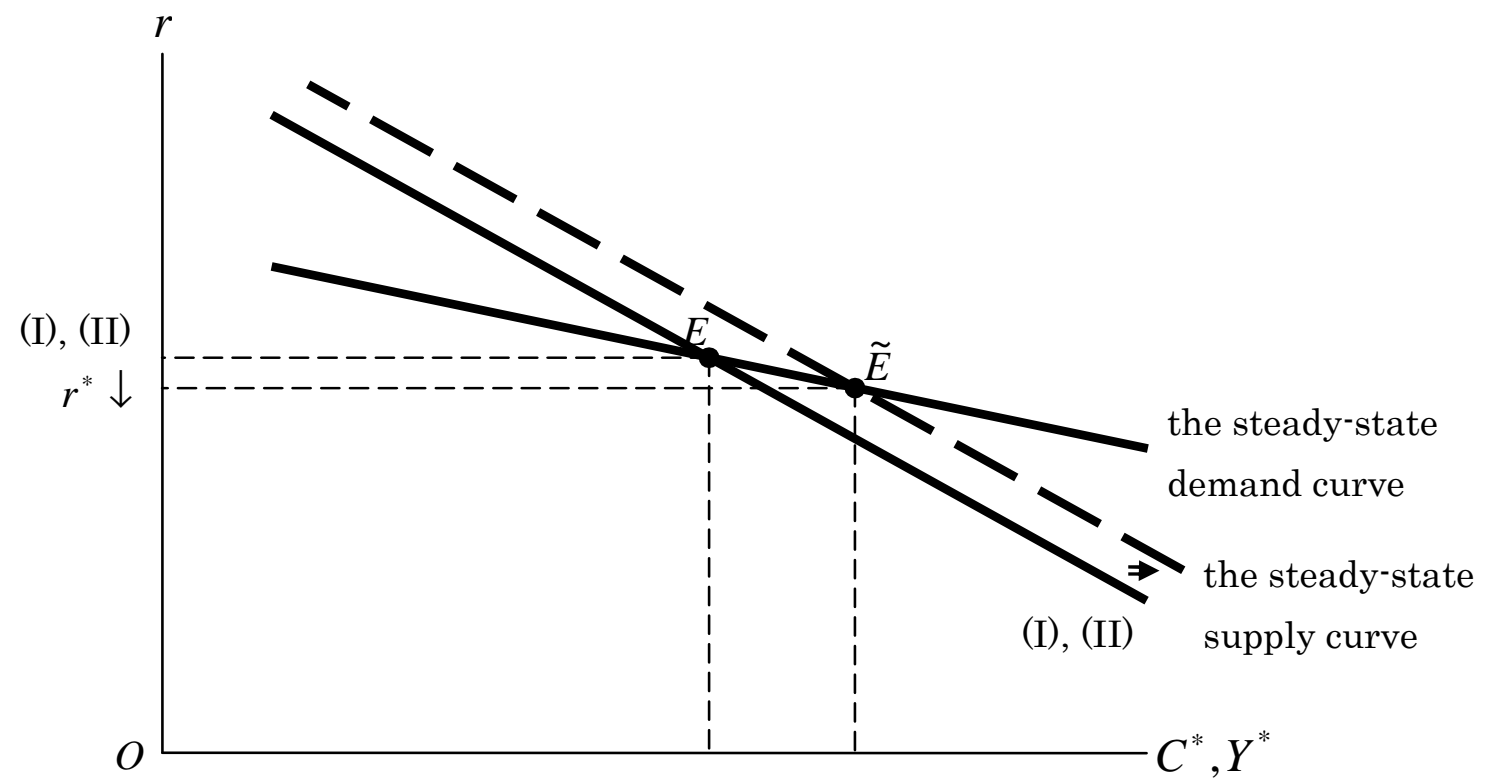

Figure 6. The effects of improvements in productivity

(I) increase in $\alpha^{1}$

(II) increase in $\alpha^{2}$ 


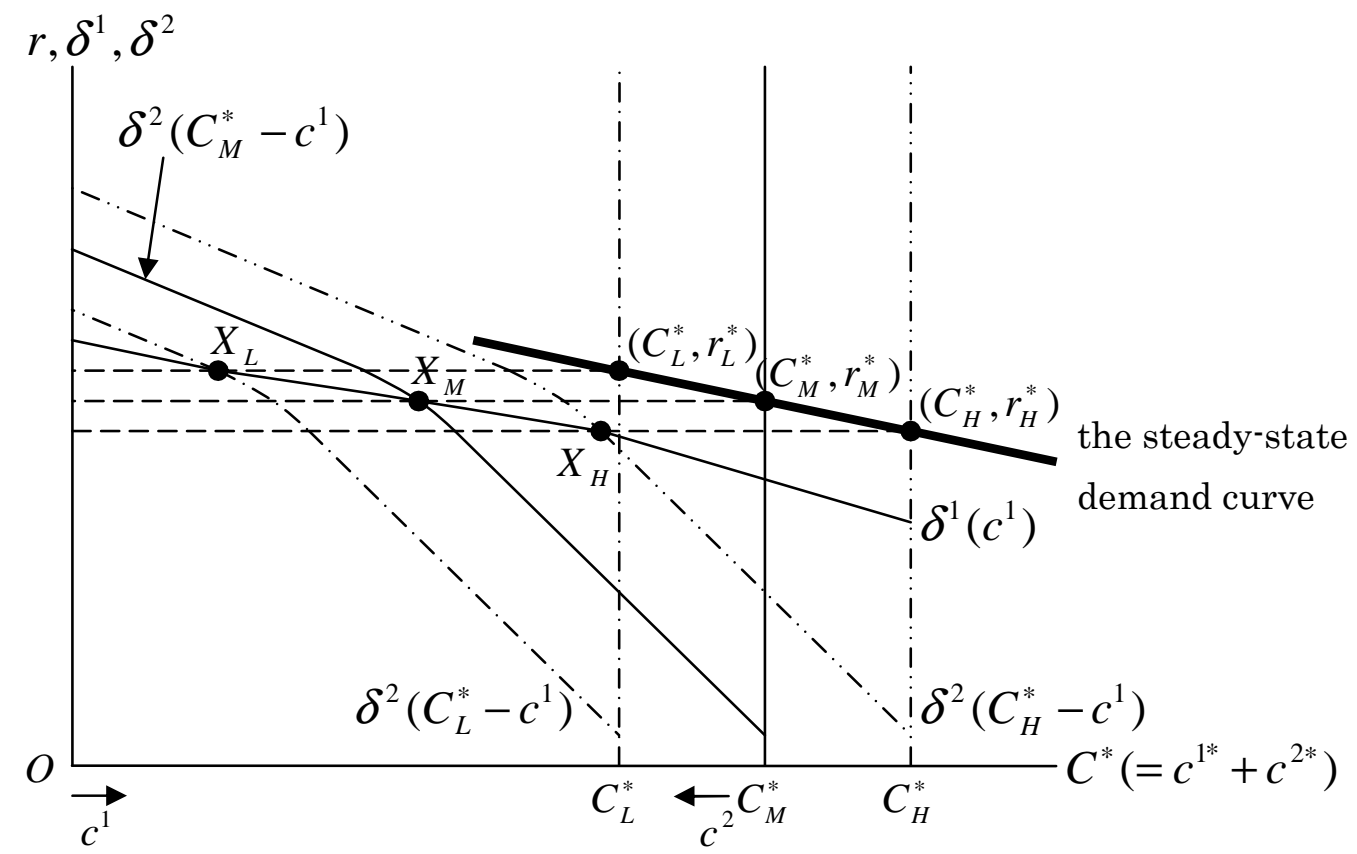

Figure A1. The derivation of the steady-state demand curve 


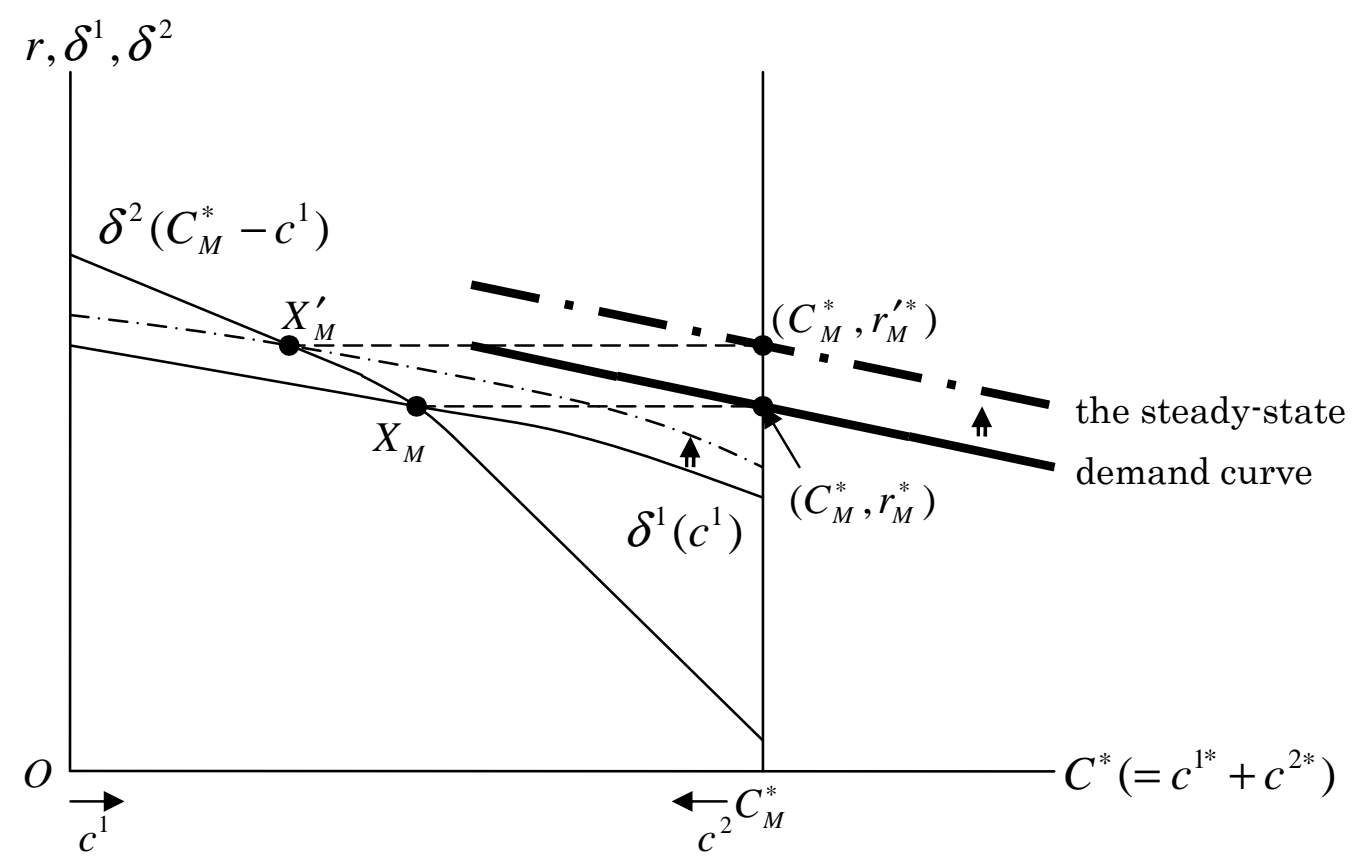

Figure A2. (i) An upward shift of the steady-state demand curve by an upward shift in $\delta^{1}$-schedule

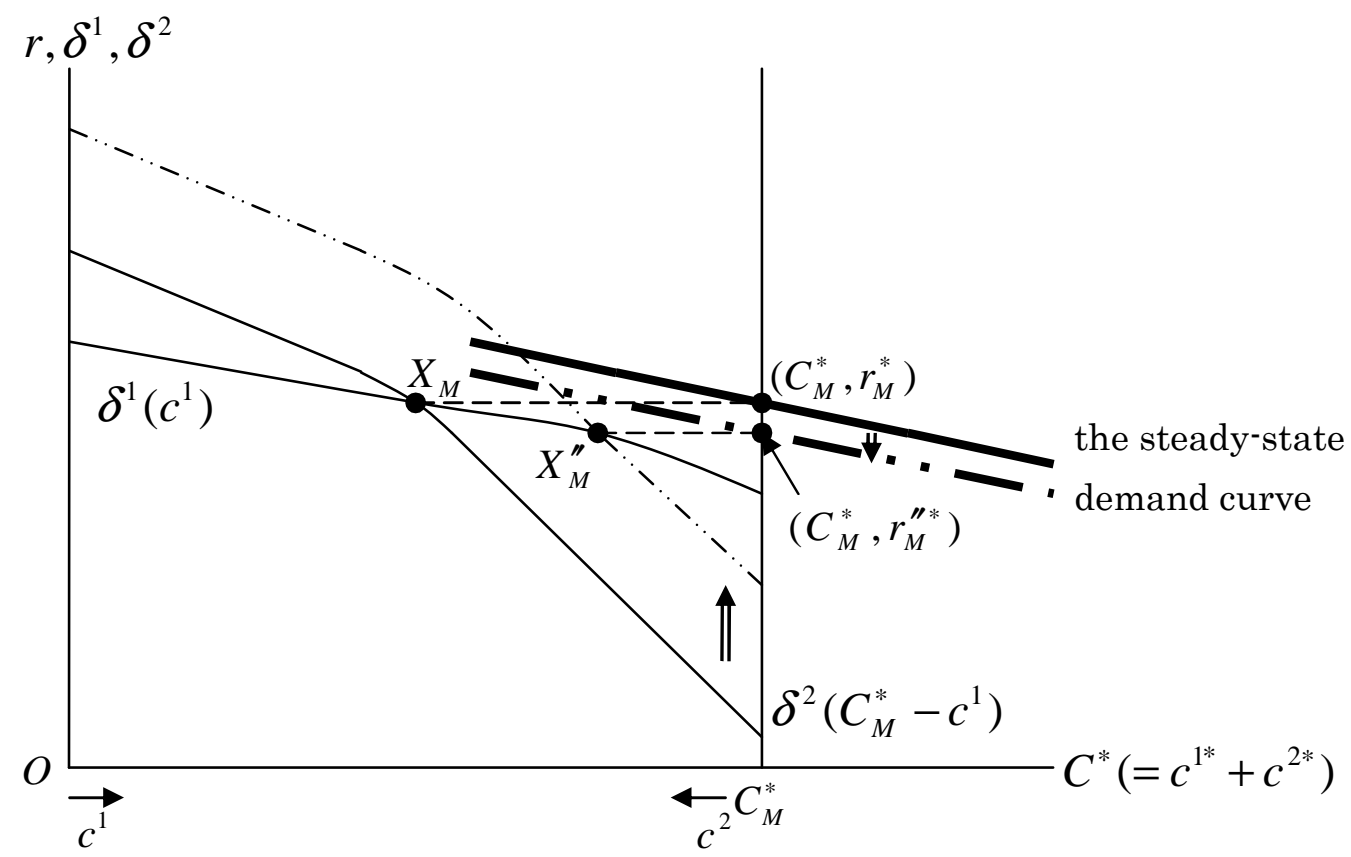

Figure A2. (ii) A downward shift of the steady-state demand curve by an upward shift in $\delta^{2}$-schedule 